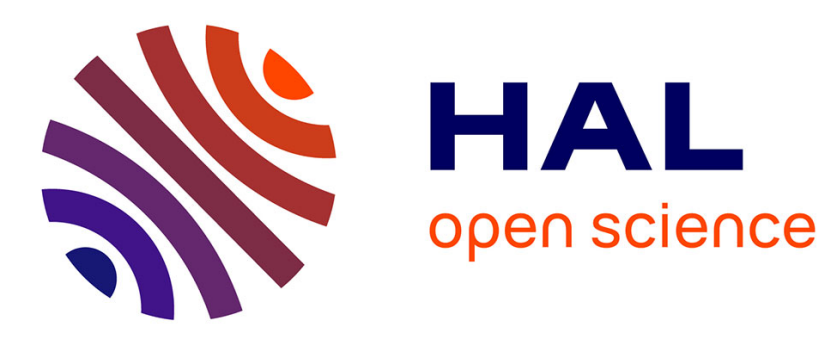

\title{
On Time-Consistent Policy Rules for Heterogeneous Discounting Programs
}

Jean-Pierre Drugeon, Bertrand Wigniolle

\section{To cite this version:}

Jean-Pierre Drugeon, Bertrand Wigniolle. On Time-Consistent Policy Rules for Heterogeneous Discounting Programs. 2015. halshs-01243669

\section{HAL Id: halshs-01243669 \\ https://shs.hal.science/halshs-01243669}

Submitted on 15 Dec 2015

HAL is a multi-disciplinary open access archive for the deposit and dissemination of scientific research documents, whether they are published or not. The documents may come from teaching and research institutions in France or abroad, or from public or private research centers.
L'archive ouverte pluridisciplinaire HAL, est destinée au dépôt et à la diffusion de documents scientifiques de niveau recherche, publiés ou non, émanant des établissements d'enseignement et de recherche français ou étrangers, des laboratoires publics ou privés. 


\section{Documents de Travail du
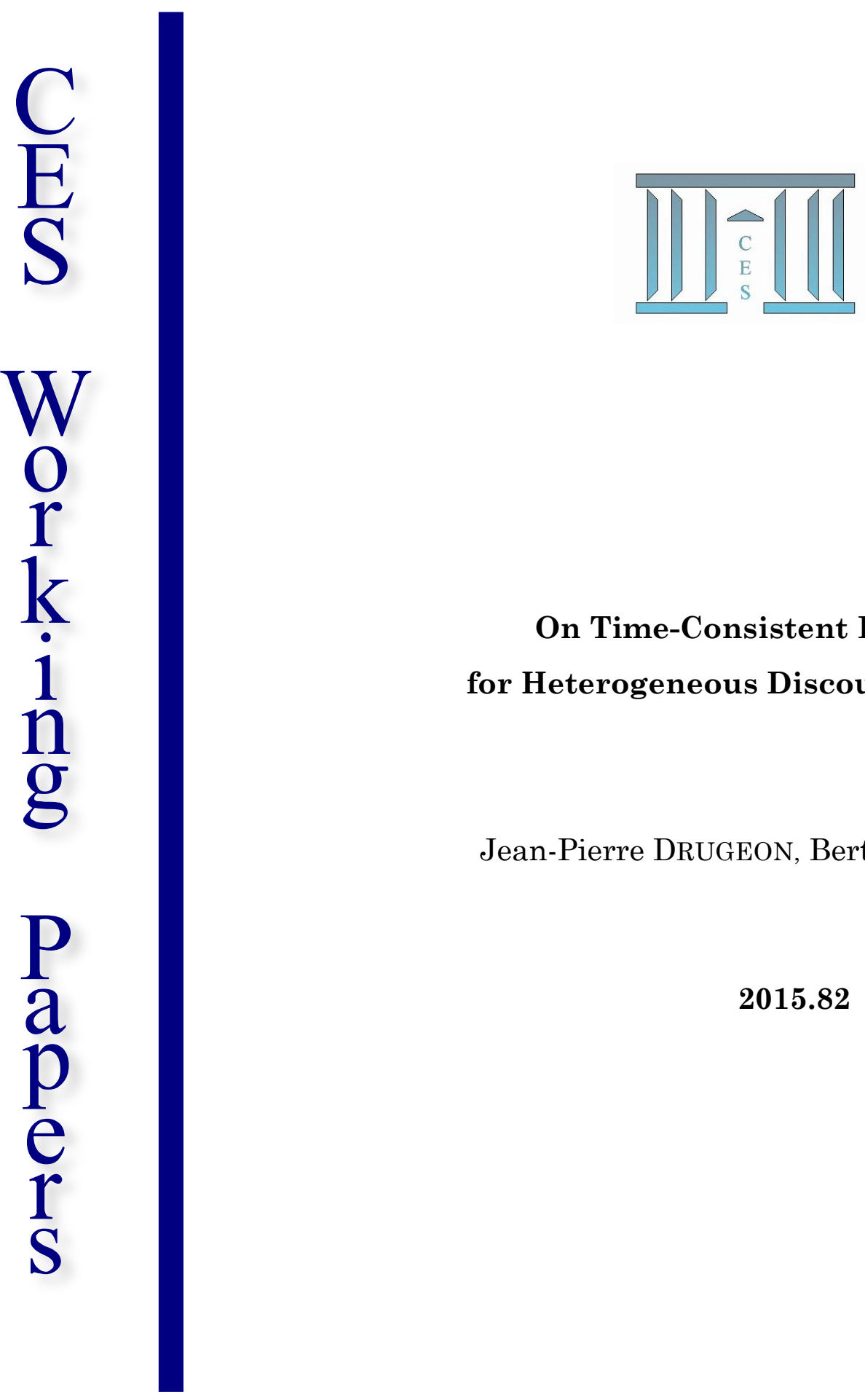

On Time-Consistent Policy Rules

for Heterogeneous Discounting Programs

Jean-Pierre DRUGEON, Bertrand WigniolLE

2015.82 


\title{
On Time-Consistent Policy Rules for Heterogeneous Discounting Programs*
}

\author{
Jean-Pierre Drugeon ${ }^{\dagger} \&$ Bertrand Wigniolle $e^{\ddagger}$

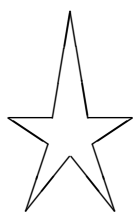

$28 / \mathrm{X} / 2015$

*This research was completed thanks to the Novo Tempus research grant, ANR-12-BSH1-0007, Program BSH1-2012. The authors would like to thank Rabah Amir and Martin Kaae Jensen for their suggestions as well as participants at the workshop on recursive methods held in Glasgow, June 2014, and the SAET conference, Tokyo, August 2014. They are also very much indebted to the two referees and the associate editor whose suggestions greatly improved the contents of this article. Final thanks to Andrew Clark for his scrutinizing help with the overall exposition.

†Paris School of Economics and Centre National de la Recherche Scientifique.

$\ddagger$ Paris School of Economics and University of Paris 1 Panthéon-Sorbonne 


\section{Abstract}

This article considers a new concept of social optimum for an economy populated by agents with heterogeneous discount factors. It is based upon an approach that constrains decision rules to be temporally consistent: these are stationary and unequivocally ruled by the state variable. For agents who differ only in their discount factors and have equal weights in the planner's objective, the temporally-consistent optimal solution produces identical consumption for the agents at all time periods. In the long run, the capital stock is determined by a modified golden rule that corresponds to an average-like summation of all discount factors. The general argument is illustrated by various two-agent examples that allow for an explicit determination of the temporally consistent decision rules. Interestingly, this temporally consistent solution can be simply recovered from the characterization of a social planner's problem with variable discounting and can also be decentralised as a competitive equilibrium through the use of various instruments.

Keywords: Time-Consistent Policy Rules, Heterogeneous Discounting Programs.

JEL Classification: $\mathrm{E}_{32}, \mathrm{O}_{41}$.

\section{Contents}

I Introduction i

II The Argument iii

II.1 A first intuition in a basic framework with two agents . . iii

II.2 A Generalized Structure . . . . . . . . . . . . . . . . . v v

II.3 The Long-Run Stationary State . . . . . . . . . . . . . . . vii

III Illustrations and Welfare Comparisons viii

III.1 A First Example . . . . . . . . . . . . . . . . . . . . . viii

III.2 A Growth Example . . . . . . . . . . . . . . . . . . . . ix

III.3 A Welfare Comparison with the Temporally-Inconsistent Optimal Decision Solution in a Simple Linear Case . . . . ix

IV Recovering the Time Consistent Optimal Solution through a Standard Discounted Optimisation Problem

V Decentralizing the Time-Consistent Optimal Solution xi

VI Proofs $\quad$ xv

VI.1 Proof of Lemma II.1 . . . . . . . . . . . . . . . . . xv

VI.2 Proof of Proposition II.1 . . . . . . . . . . . . . . . . . . . . . . xvi

VI.3 Proof of Proposition III.1 . . . . . . . . . . . . . . . xvii

VI.4 Proof of Proposition III.2 . . . . . . . . . . . . . . . xix

VI.5 Proof of Proposition III.3 . . . . . . . . . . . . . . . xxii

VI.6 Proof of Lemma IV.1 . . . . . . . . . . . . . . . . . . xxv

VI.7 Proof of Proposition IV.1 $\ldots \ldots \ldots$. . . . . . . . . . . . . . xxvi

VI.8 Proof of Corollary IV.1 . . . . . . . . . . . . . . . . . . . . xxvi

VI.9 Proof of Proposition V.1 . . . . . . . . . . . . . . xxvii 


\section{Introduction}

This article introduces a model with infinitely-lived heterogenous agents who differ from their discount factors. Consider an associated benevolent planner that is made of successive incarnations ${ }^{1}$ with the incarnation of date $t$ in charge of the decisions for that period. The objective of the date $t$-incarnation of the planner is a weighted sum of the inter temporal utilities of the agents starting from date $t$. For heterogenous discount factors, the objectives of these successive incarnations being mutually inconsistent, this article introduces a characterization of a temporally consistent solution that results from the strategic game defined between these different incarnations. This solution is arguably more robust than the commonly considered one that consists in retaining the initial objective of the date o-incarnation and assuming that it is to take the decisions for the whole horizon of dates. Indeed, all of his future decisions would be questioned by the future incarnations of the planner.

Models with heterogenous agents who differ in their valuation of the future have appeared in a large literature that has focused on the features of the associated inter-temporal equilibrium. The so-called Ramsey Conjecture - Ramsey [17] — was rigorously proved by Bewley [4] and Becker [1], and states that only the most patient of the agents ends up with positive consumption in the long run, with all other agents having zero consumption. Through the introduction of imperfect financial markets that rule out indebtedness, $R$. Becker [1] established that the long-run equilibrium exhibits the following properties: the most patient of agents holds the whole capital stock of the economy and has consumption that exceeds his wage income. ${ }^{2}$ On the contrary, all the other agents have consumption levels corresponding to their wage income. Extending the results of Bewley [4], Coles [8] and Coles [9] prove turnpike theorems when agents have different rates of time preference in multi-sectoral growth models.

The assumption of agents who differ in their valuation of the future and their discount rates has led to numerous further developments. Becker \& Foias [3] and Sorger [18] have also introduced strategic dimensions into the frameworks formally related to the imperfect financial market structure of Becker [1].

It should however be stressed that all these contributions have focused on the competitive equilibrium. To the best of our knowledge, only Becker [2] and Le Van \& Vailakis [13] have lifted the veil on the properties of the social optimum and the benevolent planner with heterogeneous discount factors. These contributions assume that the planner maximizes at an initial date a weighted sum of the inter-temporal utilities of the agents under the resource constraint of the economy. Under this assumption, the weight of the most impatient agent in the planner's objective should become arbitrarily small in the long run. The optimum tends towards a stationary state in which only the most patient agent consumes a positive amount. The long-run capital stock will be determined by a modified golden rule that corresponds to the discount factor of the most patient agent.

\footnotetext{
${ }^{1}$ This term incarnations echoes for the social planner the use of selves for the consumer in the literature on temporally inconsistent preferences.

${ }^{2} \mathrm{It}$ is worth mentioning that the Ramsey conjecture does not survive in a stochastic environment-Becker and Zilcha $[5]$ - or in settings with recursive but not necessarily additively separable preferences-Epstein $[6]$ and Epstein [7].
} 
It is worth emphasizing that the results here mimic those in the competitive equilibrium. One difficulty with this approach is that this solution is not time-consistent (and is thus not robust). Assume indeed that the date $t$-incarnation of the social planner maximises a weighted sum of the inter-temporal utilities of the agents from $t$ on; the reconsideration of this program by a later incarnation of the social planner would yield a different solution.

The current contribution suggests another approach that is temporally consistent. The decision rules of the successive incarnations of the social planner are constrained to be stationary and unequivocally ruled by the state variable (the aggregate capital stock). This approach dramatically changes the conclusions. For two agents who differ only in their discount factors and have equal weights in the planner's objective, the temporallyconsistent optimal solution predicts identical consumptions for both agents at any time period.

A generalization is presented with an unrestricted population of $n$ agents who differ in their discount factors and instantaneous utility functions, with various differentiated weights being considered in the social planner's criterion. The resulting properties are close to those in the two-agent model, with all of the agents benefitting from positive consumption in the long run. The capital stock is determined by a modified golden rule which depends on the whole set of discount factors of the agents in the economy.

The general argument is illustrated via various two-agent examples. A first one considers a Cobb-Douglas production technology and a logarithmic utility function. The framework allows for the explicit determination of the decision rules of the two individuals together with a comparison to the results in Becker [2]. A second example is then developed, based on an iso-elastic instantaneous utility function and a linear production technology. The explicit determination of decision rules continues to hold in environments that enable the emergence of endogenous growth solutions. For the temporally-consistent optimal solution, the consumptions of both agents increase at the same rate. On the contrary, in the time-inconsistent solution, the consumption of the most patient agent increases at higher rates than does that of the most impatient agent. Finally, considering the special case of a logarithmic utility function, it is also possible to calculate the explicit values of the inter-temporal utilities of the two agents, both for the time-consistent solution and the standard optimal solution. In this example, even though it is established that the most impatient agent benefits from higher utility in the time-consistent solution, total welfare in the time consistent solution is lower than that in the standard optimum.

It is also proved that the temporally consistent solution can be simply recovered from the characterization of a standard social planner's problem with a recursive objective function and a variable discounting term. This term is a weighted sum of the agents' discount factors. Interestingly, and for the earlier simple parametric examples, the discounting term is constant and an explicit form becomes available for the value function of the social planner. The final part of our work illustrates how a time-consistent optimal solution can be decentralized as a competitive equilibrium through the use of three instruments, namely distortionary taxation on the capital stock that is specific to each agent, the issuance of public debt, and an initial transfer of wealth between agents. Moreover, at the steady state the relatively impatient agent should be subsidized while the relatively patient one should be taxed.

Section II introduces the basic solution concept for the case of two agents, and then enlarges 
the analysis to $n$ agents who may differ in both their discount factors and their instantaneous utility functions, the analysis being completed by introducing different weights in the social planner's objective function. Section III investigates three examples, Section IV explains how the solution concept can be simply recovered from the characterization of a standard social planner's program with variable discounting and Section V eventually addresses the decentralization of the time-consistent optimal solution. All proofs are brought together in a final appendix.

\section{The Argument}

\section{II.1 A first intuition in a basic framework with two agents}

Time is discrete. The economy consists of two infinitely-lived individuals indexed by $i \in$ $\{1,2\}$ who differ in their discount factors. Let then $\left\{c_{t}^{i}\right\}, t \in \mathbb{N}$, denote the consumption sequence of agent $i$, for $c_{t}^{i} \in \mathbb{R}_{+}$. His preferences are represented by an inter-temporal utility function of the following kind:

$$
\mathrm{U}\left(\left\{c_{t}^{i}\right\}\right)=\sum_{t=0}^{+\infty}\left(\delta_{i}\right)^{t} u\left(c_{t}^{i}\right)
$$

This economy includes a competitive representative firm with a production function $\mathrm{F}\left(\mathrm{K}_{t}, \mathrm{~L}_{t}\right)$, with $\mathrm{K}_{t}$ the capital stock at date $t \in \mathbb{N}$ that depreciates at the rate $\left.\eta \in\right]_{0}, 1[$, and $\mathrm{L}_{t}$ the quantity of labour at that same date. All individuals inelastically offer $1 / 2$ units of labour, so that the global amount that is offered sums to 1. The resource constraint is as follows for the economy at a given date $t \in \mathbb{N}$ :

(1) $\mathrm{K}_{t+1}=\mathrm{F}\left(\mathrm{K}_{t}, 1\right)+(1-\eta) \mathrm{K}_{t}-\sum_{i=1}^{2} c_{t}^{i}$.

In both Le Van and Vailakis [13] and Becker [2], the objective function of the planner is the sum of the inter-temporal utility functions of the two agents up to date o:

(2) $\sum_{t=0}^{+\infty} \sum_{i=1}^{2}\left(\delta_{i}\right)^{t} u\left(c_{t}^{i}\right)$

The planner determines the optimal sequences of $\left\{c_{t}^{1}\right\}$ and $\left\{c_{t}^{2}\right\}$ by maximizing at date $t=\mathrm{o}$ the objective $(2)$ under the resource constraint $(1)$. The preceding objective function accordingly can be rewritten as:

(3) $\sum_{t=0}^{+\infty}\left(\delta_{1}\right)^{t}\left[u\left(c_{t}^{1}\right)+\left(\delta_{2} / \delta_{1}\right)^{t} u\left(c_{t}^{2}\right)\right]$

As $\delta_{2}<\delta_{1}$, the component $\left(\delta_{2} / \delta_{1}\right)^{t}$ asymptotically converges to zero for infinite values of $t$. The weight associated to the consumption of the relatively impatient agent 2, namely $c_{t}^{2}$, then becomes negligible for large values of $t$. Becker [2] and Le Van \& Vailakis [13] in their Proposition 8 indeed find that consumption $c_{t}^{2}$ converges to o in the long run.

Consider instead that the planner builds from successive incarnations, the date- $t$ incarnation being in charge of the decisions for period $t$. Such an approach mimics the one 
on the literature on time-inconsistent preferences initiated by Strotz [19] and Phelps and Pollack [16]. Compare the objectives of two distinct incarnations of the social planner. First consider the date o-incarnation objective function given by (2). Then consider the date $t$-incarnation of the social planner. The intertemporal utility function of agent $i$ from $t$ on is:

$$
\sum_{\tau=0}^{+\infty}\left(\delta_{i}\right)^{\tau} u\left(c_{t+\tau}^{i}\right) .
$$

The objective of the incarnation by date $t$ of the social planner hence becomes:

(4) $\quad \sum_{\tau=0}^{+\infty} \sum_{i=1}^{2}\left(\delta_{i}\right)^{\tau} u\left(c_{t+\tau}^{i}\right)$.

In the first formulation (2) of the objective, the period- $t$ element is $\left(\delta_{1}\right)^{t}\left[u\left(c_{t}^{1}\right)+\right.$ $\left.\left(\delta_{2} / \delta_{1}\right)^{t} u\left(c_{t}^{2}\right)\right]$. However, with formulation $(4)$, it is $\sum_{i=1}^{2} u\left(c_{t}^{i}\right)$. This proves that, as a direct byproduct of the heterogeneity of discount factors amongst the individual agents, the objective of the incarnation at date $t$ of the social planner is not consistent with the one of its incarnation at date o. Otherwise stated, would the incarnation at date o of the social planner be in position to take the whole sequence of decisions from date o to $+\infty$, he would select for date $t$ a class of decisions that differ from its incarnation at date $t$. Heterogeneity in discount factors hence leads to temporal inconsistency in the sequential incarnations of the planner's choices.

In opposition to this, the cornerstone of the current analysis is the imposition of temporal consistency for the choices of successive planners. By assumption, decision rules will be functions that unequivocally depend on the state variable - the capital stock- under consideration:

$$
c_{t}^{i}=\vartheta_{\mathrm{C}}^{i}\left(\mathrm{~K}_{t}\right) .
$$

The solution then comes from a strategic game between the successive incarnations of the planner: the incarnation at date $t$ determines the best resource allocation at $t$, having taken into account that all future incarnations of the planner will apply the strategy $c_{t+\tau}^{i}=\vartheta_{\mathrm{C}}^{i}\left(\mathrm{~K}_{t+\tau}\right)$. This assumption hence ensures time consistency in the optimal choices of the successive social planners.

The solution concept for this game is similar to the one that was used in the literature on time inconsistency of the consumer problem initiated by Phelps and Pollack [16]. The social planner is therein viewed as successive incarnations and the decision at date $t$ is taken by the $t$-th incarnation. Phelps and Pollack [16] went on labelling their equilibrium concept as a Cournot-Nash Equilibrium. In the recent literature on hyperbolic discounting, various names have however been used for this same solution concept. Judd [11] introduces the seemingly most precise terminology for this equilibrium that is referred as a continuous differentiable Nash equilibrium. Such a terminology singles out the focus on smooth functions that remained implicit in most of the articles of the literature. The most common name for this solution concept is however the one of Markov equilibrium - vid., e.g, Harris and Laibson [10] or Krussel and Smith [12]. It is also to be mentioned that this solution concept is at times referred in an intuitive way as describing a sophisticated behaviour. 
As the solution $\left(\vartheta_{\mathrm{C}}^{1}\left(\mathrm{~K}_{t}\right), \vartheta_{\mathrm{C}}^{2}\left(\mathrm{~K}_{t}\right)\right)$ is constrained to be temporally consistent, it is consistent with the case in which the planner reconsiders the maximization program every time period. For a maximization at date $t$, the instantaneous reward by that period is $u\left(c_{t}^{1}\right)+$ $u\left(c_{t}^{2}\right)$ while the associated costs are $c_{t}^{1}+c_{t}^{2}$. The optimal time-consistent solution will naturally be associated with two identical consumptions: $\vartheta_{\mathrm{C}}^{1}\left(\mathrm{~K}_{t}\right)=\vartheta_{\mathrm{C}}^{2}\left(\mathrm{~K}_{t}\right)$ for any $\mathrm{K}_{t} \geqslant$ o. In particular, the long-run consumption of the relatively impatient agent no longer asymptotically tends to o.

\section{II.2 A Generalized Structure}

Consider now an environment with $n$ heterogeneous agents who first differ in their instantaneous utility function $u^{i}(\cdot), i \in\{1,2, \ldots, n\}$ :

Assumption P1. $u^{i}(\cdot)$ is defined on $\mathbb{R}_{+}$, of class $\mathscr{C}^{2}$, with $\mathrm{D} u^{i}\left(c^{i}\right)>0^{3}, \mathrm{D}^{2} u^{i}\left(c^{i}\right)<0$, for $c^{i}>0$ and $\left.\mathrm{D} u^{i}(\mathrm{o})=+\infty, \mathrm{D} u^{i}(+\infty)=0, \delta_{i} \in\right] \mathrm{o}, 1[, i \in\{1,2, \ldots, n\}$.

Agents are also ranked according to their discount factors:

Assumption P2. $1>\delta_{1}>\delta_{2}>\cdots>\delta_{n}>$ o.

Finally, agents' utilities are weighted by factors $\lambda_{1}, \ldots, \lambda_{n}$ in the objective of the benevolent planner. The productive sector remains unmodified with respect to the basic argument of section II.1 and the production technology satisfies:

Assumption T1.: $\mathrm{F}(\mathrm{K}, \mathrm{L})$ is a function of class $\mathscr{C}^{2}$, homogeneous of degree one, increases with $\mathrm{K}$ as $\mathrm{D}_{\mathrm{K}} \mathrm{F}(\mathrm{K}, 1)>0$, and is concave with $\mathrm{D}_{\mathrm{KK}}^{2} \mathrm{~F}(\mathrm{~K}, 1)<\mathrm{o}$ for $\mathrm{K}>$ o. Moreover, $\mathrm{D}_{\mathrm{K}} \mathrm{F}(\mathrm{o}, 1)>1 / \delta_{n}-(1-\eta)$ and $\mathrm{D}_{\mathrm{K}} \mathrm{F}(+\infty, 1)<1 / \delta_{1}-(1-\eta)$.

The resource constraint is:

(5) $\mathrm{K}_{t+1}=\mathrm{F}\left(\mathrm{K}_{t}, 1\right)+(1-\eta) \mathrm{K}_{t}-\sum_{i=1}^{n} c_{t}^{i}$.

Let $\vartheta_{\mathrm{C}}^{i}\left(\mathrm{~K}_{t}\right)$ denote the consumption decision rule for agent $i$, while $J^{i}\left(\mathrm{~K}_{t}\right)$ is the resulting payoff function, defined as:

(6) $\mathrm{J}^{i}\left(\mathrm{~K}_{t}\right)=\sum_{\tau=0}^{+\infty}\left(\delta_{i}\right)^{\tau} u^{i}\left[\vartheta_{\mathrm{C}}^{i}\left(\mathrm{~K}_{t+\tau}\right)\right], i \in\{1,2, \ldots, n\}$,

for $\left\{\mathrm{K}_{t+\tau}\right\}_{\tau \geqslant 0}$ recursively defined through $\mathrm{K}_{t+\tau+1}=\mathrm{F}\left(\mathrm{K}_{t+\tau}, 1\right)+(1-\eta) \mathrm{K}_{t+\tau}-$ $\sum_{i=1}^{n} \vartheta_{\mathrm{C}}^{i}\left(\mathrm{~K}_{t+\tau}\right)$.

Assumption T2.: $\mathrm{J}^{i}\left(\mathrm{~K}_{t}\right), i \in\{1,2, \ldots, n\}$ is a well-defined function from $\mathbb{R}_{+}$into $\mathbb{R}$, that is of class $\mathscr{C}^{2}$, strictly increasing and concave.

Consider then:

(7a) $\mathrm{W}\left(\mathrm{K}_{t}\right)=\sum_{i=1}^{n} \lambda_{i} \mathrm{~J}^{i}\left(\mathrm{~K}_{t}\right)$

${ }^{3}$ The notation $\mathrm{D} u^{i}\left(c^{i}\right)=\partial u^{i}\left(c^{i}\right) / \partial c^{i}$ will be retained throughout the text. 
(7b) $\mathrm{W}^{\Delta}\left(\mathrm{K}_{t}\right)=\sum_{i=1}^{n} \lambda_{i} \delta_{i} \mathrm{~J}^{i}\left(\mathrm{~K}_{t}\right)$

for $\Delta:=\left(\delta_{1}, \delta_{2}, \ldots, \delta_{n}\right)$ that denotes the vector of heterogeneous discount rates. The consumption decision rules now emerge as the solutions to the following program:

$$
\mathrm{W}\left(\mathrm{K}_{t}\right)=\max _{\left\{c_{t}^{i}\right\}}\left\{\sum_{i=1}^{n} \lambda_{i} u^{i}\left(c_{t}^{i}\right)+\mathrm{W}^{\Delta}\left(\mathrm{K}_{t+1}\right) \text { s.t. } \mathrm{K}_{t+1}=\mathrm{F}\left(\mathrm{K}_{t}, 1\right)+(1-\eta) \mathrm{K}_{t}-\sum_{i=1}^{n} c_{t}^{i}\right\} .
$$

The first-order conditions are then:

(8) $\quad \lambda_{i} \mathrm{D} u^{i}\left(c_{t}^{i}\right)=\mathrm{DW}^{\Delta}\left(\mathrm{K}_{t+1}\right)$ for any $i \in\{1,2, \ldots, n\}$.

This in turn implies that the following relationship between two heterogeneous individuals holds:

(9) $\quad \lambda_{i} \mathrm{D} u^{i}\left(c_{t}^{i}\right)=\lambda_{j} \mathrm{D} u^{j}\left(c_{t}^{j}\right)$ for any $i, j$.

The resource constraint $(5)$ and consumption decision rules $\vartheta_{\mathrm{C}}^{i}\left(\mathrm{~K}_{t}\right)$ allow us to determine the investment decision rule as

(10) $\vartheta_{\mathrm{K}}\left(\mathrm{K}_{t}\right)=\mathrm{F}\left(\mathrm{K}_{t}, 1\right)+(1-\eta) \mathrm{K}_{t}-\sum_{i=1}^{n} \vartheta_{\mathrm{C}}^{i}\left(\mathrm{~K}_{t}\right)$.

REMARK II.1. If $\lambda_{i}=\lambda_{j}$ and $u^{i}=u^{j}$ for any $i, j$, we have that $c_{t}^{i}=c_{t}^{j}$. All consumptions are equal at all periods, even for agents who differ in their discount rates.

Remark II.2. For an iso-elastic parametric formulation of the individual utilities $u^{i}\left(c^{i}\right)=$ $\left(c^{i}\right)^{1-1 / \xi} /(1-1 / \xi), \xi \neq 1$, the above relations between the individual agents lead to $c_{t}^{i} / c_{t}^{j}=$ $\left(\lambda_{i} / \lambda_{j}\right)^{\xi}$. The ratio between the consumption of the two agents will be constant, a property that is at odds with the results in Becker [2] and Le Van and Vailakis [13].

Lemma II.1..- All of the functions $\vartheta_{\mathrm{K}}\left(\mathrm{K}_{t}\right)$ and $\vartheta_{\mathrm{C}}^{i}\left(\mathrm{~K}_{t}\right), i \in\{1,2, \ldots, n\}$, that feature the investment and consumption policy rules are of class $\mathscr{C}^{1}$ and are increasing.

The envelope condition is derived as:

(11) $\mathrm{DW}\left(\mathrm{K}_{t}\right)=\mathrm{DW}^{\Delta}\left(\mathrm{K}_{t+1}\right)\left[\mathrm{D}_{\mathrm{K}} \mathrm{F}\left(\mathrm{K}_{t}, 1\right)+(1-\eta)\right]$.

For any individual $i \in\{1,2, \ldots, n\}$, the derivative of the payoff function is:

(12) $\operatorname{DJ}^{i}\left(\mathrm{~K}_{t}\right)=\mathrm{D} u^{i}\left[\vartheta_{\mathrm{C}}^{i}\left(\mathrm{~K}_{t}\right)\right] \mathrm{D} \vartheta_{\mathrm{C}}^{i}\left(\mathrm{~K}_{t}\right)+\delta_{i} \mathrm{D}_{\mathrm{K}_{\mathrm{K}}}\left(\mathrm{K}_{t}\right) \mathrm{DJ}^{i}\left(\mathrm{~K}_{t+1}\right)$.

At this stage, it is however worth noting that as none of the functions $\vartheta_{\mathrm{C}}^{i}\left(\mathrm{~K}_{t}\right)$ is an optimal solution for the problem of any of the individuals, there is no possibility of eliminating $\mathrm{D} \vartheta_{\mathrm{C}}^{i}\left(\mathrm{~K}_{t}\right)$ between the above equations and recovering a Euler-type equation. 


\section{II.3 The Long-Run Stationary State}

The existence of a stationary state is assumed and associated with constant values for the investment $K=\vartheta_{K}(K)$ and consumption $c^{i}=\vartheta_{\mathrm{C}}^{i}(K)$ decision rules. A stationary state satisfies the following conditions:

(13a) $\sum_{i=1}^{n} \vartheta_{\mathrm{C}}^{i}(\mathrm{~K})=\mathrm{F}(\mathrm{K}, 1)-{ }_{\eta} \mathrm{K}$,

$\left({ }_{13} \mathrm{~b}\right) \lambda_{i} \mathrm{D} u^{i}\left[\vartheta_{\mathrm{C}}^{i}(\mathrm{~K})\right]=\mathrm{DW}^{\Delta}(\mathrm{K})$,

(13c) $\mathrm{DW}(\mathrm{K})=\left[\mathrm{D}_{\mathrm{K}} \mathrm{F}(\mathrm{K}, 1)+1-\eta\right] \mathrm{DW}^{\Delta}(\mathrm{K})$,

$\left({ }_{13} \mathrm{~d}\right) \mathrm{DJ}^{i}(\mathrm{~K})=\left\{1-\delta_{i} \mathrm{D} \vartheta_{\mathrm{K}}(\mathrm{K})\right\}^{-1} \mathrm{D} u^{i}\left[\vartheta_{\mathrm{C}}^{i}(\mathrm{~K})\right] \mathrm{D} \vartheta_{\mathrm{C}}^{i}(\mathrm{~K})$,

(13е) $\mathrm{DW}(\mathrm{K})=\sum_{i=1}^{n} \lambda_{i} \mathrm{DJ}{ }^{i}(\mathrm{~K})$

$\left({ }_{13} \mathrm{f}\right) \mathrm{DW}^{\Delta}(\mathrm{K})=\sum_{i=1}^{n} \lambda_{i} \delta_{i} \mathrm{DJ}^{i}(\mathrm{~K})$.

$(13 \mathrm{~g}) \vartheta_{\mathrm{K}}(\mathrm{K})=\mathrm{F}(\mathrm{K}, 1)+(1-\eta) \mathrm{K}-\sum_{i=1}^{n} \vartheta_{\mathrm{C}}^{i}(\mathrm{~K})$.

While equation (13a) corresponds to the steady-state expression of the resource constraint (5), equation $(13 \mathrm{~b})$ features the first-order condition for the individual agent (8). Equation $(13 \mathrm{c})$ gives the envelope condition $(11)$, while equation $\left({ }_{13} \mathrm{~d}\right)$ is the steady-state value of inter-temporal utility for agent $i(12)$. Last, equations $(13 \mathrm{e})$ and $(13 \mathrm{f})$ result from the definition of the functions $\mathrm{W}(\cdot)$ and $\mathrm{W}^{\Delta}(\cdot)$ when they are considered at the steady state and $(13 \mathrm{~g})$ results from equation $(10)$.

Proposition II.1.- Under the previous assumptions, consider a steady state:

(i) The steady-state marginal productivity of the capital stock is a solution to a generalized modified golden rule for which all of the discount factors come into play:

$$
\begin{aligned}
& \left\{\sum_{i=1}^{n} \frac{\delta_{i} \mathrm{D} \vartheta_{\mathrm{C}}^{i}(\mathrm{~K})}{1-\delta^{i}\left[\mathrm{D}_{\mathrm{K}} \mathrm{F}(\mathrm{K}, 1)+1-\eta-\sum_{i=1}^{n} \mathrm{D} \vartheta_{\mathrm{C}}^{i}(\mathrm{~K})\right]}\right\}\left[\mathrm{D}_{\mathrm{K}} \mathrm{F}(\mathrm{K}, 1)+(1-\eta)\right] \\
& =\left\{\sum_{i=1}^{n} \frac{\mathrm{D} \vartheta_{\mathrm{C}}^{i}(\mathrm{~K})}{1-\delta^{i}\left[\mathrm{D}_{\mathrm{K}} \mathrm{F}(\mathrm{K}, 1)+1-\eta-\sum_{i=1}^{n} \mathrm{D} \vartheta_{\mathrm{C}}^{i}(\mathrm{~K})\right]}\right\} .
\end{aligned}
$$

(ii) Marginal productivity belongs to the interval $] 1 / \delta_{1}, 1 / \delta_{n}[$.

Proposition II.1 illustrates how the steady-state economy exhibits a modified golden rule that corresponds to an average discount parameter $1 / \delta \in] 1 / \delta_{1}, 1 / \delta_{n}[$ : the long-run is no longer unequivocally determined by the most patient agent.

Remark II.3. The stationary state depends upon $\mathrm{D} \vartheta_{\mathrm{C}}^{i}(\mathrm{~K}), i \in\{1,2, \ldots, n\}$, the expressions of which are unknown. Some subsequent examples shall however illustrate special cases for which there are explicit formulations for the consumption decision rules and thus for the other components at the steady state. 
Remark II.4. Assuming that the temporally-consistent solution to the planner's problem converges to a limit state $\mathrm{K}$ with $c=\vartheta_{\mathrm{C}}^{i}(\mathrm{~K}), i \in\{1,2, \ldots, n\}$, the latter will correspond to a stationary state. Starting from $K_{0}=K$, given a set of decision rules that are unequivocally determined by the state, the economy will not depart from this state. Interestingly, this property contrasts with that in Le Van \& Vailakis [13], whose analysis is based on a solution that is not time-consistent.

\section{Illustrations and Welfare Comparisons}

\section{III.1 A First Example}

This is directly adapted from Becker [2]. The economic environment consists of two agents with logarithmic instantaneous utility functions $u(c)=\ln (c)$ and a production technology of the Cobb-Douglas variety with $\left.\mathrm{F}(\mathrm{K}, 1)=\mathrm{AK} \mathrm{K}^{\alpha}, \alpha \in\right]_{0,1}[$ and $\mathrm{A}>\mathrm{o}$, the rate of depreciation of the capital stock being unitary over a given period. The objective of the planner is assumed to be: $W(K)=\sum_{i=1}^{2} \lambda_{i} J^{i}(K)$, for $\left.\lambda_{i} \in\right] \mathrm{o}, 1\left[\right.$ and $\sum_{i=1}^{2} \lambda_{i}=1$.

Proposition III.1.- Consider an economy with log preferences and Cobb-Douglas technology:

(i) the payoff functions of the two individuals are as follows:

$$
\mathrm{J}^{i}\left(\mathrm{~K}_{t}\right)=\frac{\alpha}{1-\alpha \delta_{i}} \ln \left(\mathrm{K}_{t}\right)+b_{i},
$$

for some constant parameter $b_{i}$;

(ii) the consumption and investment decision rules are:

$$
\begin{gathered}
c_{t}^{i}=\frac{\lambda_{i} \mathrm{~A}\left(\mathrm{~K}_{t}\right)^{\alpha}}{1+\mu}, \\
\mathrm{K}_{t+1}=\mathrm{A}\left(\mathrm{K}_{t}\right)^{\alpha} \frac{\mu}{1+\mu}, \\
\text { for } \mu=\sum_{i=1}^{2} \lambda_{i} \delta_{i} a_{i} ;
\end{gathered}
$$

(iii) the capital stock converges to a value $\mathrm{K}$ such that:

$$
\mathrm{AK}^{\alpha-1}=\frac{\sum_{i=1}^{2} \lambda_{i} /\left(1-\alpha \delta_{i}\right)}{\sum_{i=1}^{2} \lambda_{i} \alpha \delta_{i} /\left(1-\alpha \delta_{i}\right)} ;
$$

This range of results may then fruitfully be compared to those in Becker [2]. The stationary state there corresponds to the modified golden rule of the most patient agent:

$$
\mathrm{AK}^{\alpha-1}=\frac{1}{\alpha \delta_{1}}
$$

the consumption of the impatient agent 2 converges asymptotically to o. On the contrary, here the long-run steady state corresponds to the modified golden rule associated with a value $\delta \in] \delta_{2}, \delta_{1}[$, in which both agents have positive consumption in all periods.

More specifically and for $\lambda_{i}=1 / 2$, the two agents' consumptions are equal: $c_{t}^{1}=c_{t}^{2}$ for any $t \in \mathbb{N}$. Comparing the equations for the long-run value of $\mathrm{K}$, it can further be shown that $\mathrm{D} \vartheta_{\mathrm{K}}(\mathrm{K})=\mathrm{D}_{\mathrm{K}} \mathrm{F}(\mathrm{K}, 1)-{ }_{2} \mathrm{D} \vartheta_{\mathrm{C}}(\mathrm{K})=\alpha$. 


\section{III.2 A Growth Example}

The economy here consists of two agents with common iso-elastic instantaneous utility functions $u(c)=(c)^{1-1 / \varsigma} /(1-1 / \varsigma), \varsigma \neq 1$ and a linear production technology $\mathrm{F}(\mathrm{K}, 1)=$ $\mathrm{AK}$, with $\mathrm{A}>0$, the rate of depreciation of the capital stock being unitary over a given period and $\eta=1$. The planner's objective is again given by $W(K)=\sum_{i=1}^{2} \lambda_{i} J^{i}(K)$, for $\left.\lambda_{i} \in\right] \mathrm{o}, 1\left[, \sum_{i=1}^{2} \lambda_{i}=1\right.$

Proposition III.2.- Consider the environment with iso-elastic utilities and a linear production technology under the assumption that $\delta_{1} \mathrm{~A}^{(\varsigma-1) / \varsigma}<1$ :

(i) the payoff functions of the two individuals are given by:

$$
\begin{aligned}
\mathrm{J}^{i}\left(\mathrm{~K}_{t}\right)=\frac{1}{1-1 / \varsigma}\left(\frac{\lambda_{i}}{\mu}\right)^{\varsigma-1}\left(\mathrm{~K}_{t}\right)^{1-1 / \varsigma}( & \left.\frac{\mathrm{A}}{\mathrm{B}(\mu)}\right)^{(\varsigma-1) / \varsigma} \\
& \times \frac{1}{1-\delta_{i}(\mathrm{~A} / \mathrm{B}(\mu))^{(\varsigma-1) / \varsigma}}, i \in\{1,2\},
\end{aligned}
$$

where $\mathrm{B}(\mu)=1+\sum_{i=1}^{2}\left(\lambda_{i} / \mu\right)^{\varsigma}$ and $\mu$ is the unique solution to the following equation:

$$
\mu^{\varsigma}=\sum_{i=1}^{2}\left(\lambda_{i}\right)^{\varsigma} \frac{\delta_{i}}{(\mathrm{~B}(\mu) / \mathrm{A})^{(\varsigma-1) / \varsigma}-\delta_{i}} ;
$$

(ii) the consumption and decision rules that are obtained as solutions to the temporallyinconsistent optimisation program at date o are:

$$
\begin{aligned}
c_{t+\tau}^{i} & =\left(\frac{\lambda_{i}}{\mu}\right)^{\varsigma}\left(\frac{\mathrm{A}}{\mathrm{B}(\mu)}\right)^{\tau+1} \mathrm{~K}_{t}, i \in\{1,2\}, \\
\mathrm{K}_{t+\tau} & =\left(\frac{\mathrm{A}}{\mathrm{B}(\mu)}\right)^{\tau} \mathrm{K}_{t} .
\end{aligned}
$$

(iii) the consumption levels at the temporally-inconsistent solution are:

$$
c_{t}^{i}=\frac{\left(\lambda_{i}\right)^{\varsigma}\left(\delta_{i}\right)^{\varsigma t} \mathrm{~A}^{\varsigma(t+1)} \mathrm{K}_{\mathrm{o}}}{\sum_{\tau=0}^{+\infty} \sum_{j=1}^{2}\left(\lambda_{j}\right)^{\varsigma}\left(\delta_{j}\right)^{\tau \varsigma} \mathrm{A}^{(\varsigma-1)(\tau+1)}}, \quad i \in\{1,2\} .
$$

For the temporally-consistent optimal solution, the two agents' consumptions exhibit an identical growth rate. On the contrary, at the temporally-inconsistent solution the consumption of the relatively patient agent rises at a higher rate than that of the relatively impatient agent.

\section{III.3 A Welfare Comparison with the Temporally-Inconsistent Optimal Decision Solution in a Simple Linear Case}

To cut down on the calculations, this illustration is based on a slightly simplified version of the preceding growth example in which $\varsigma=1$.

Proposition III.3.- Consider an environment with logarithmic preferences and a linear production technology. 
(i) For the most patient agent, the payoff of the time-invariant solution $\mathrm{J}^{1}\left(\mathrm{~K}_{\mathrm{o}}\right)$ is lower than that in the optimal time-inconsistent solution $\mathrm{U}_{1}$, the difference being given by:

$$
\mathrm{J}^{1}\left(\mathrm{~K}_{\mathrm{o}}\right)-\mathrm{U}_{1}=\frac{\delta_{1}}{\left(1-\delta_{1}\right)^{2}}\left\{\ln \left[\frac{\sum_{j=1}^{2}\left[\lambda_{j} \delta_{j} /\left(1-\delta_{j}\right)\right]}{\sum_{j=1}^{2}\left[\lambda_{j} /\left(1-\delta_{j}\right)\right]}\right]-\ln \left(\delta_{1}\right)\right\}<0
$$

(ii) For the most impatient agent, the payoff of the time-invariant solution $\mathrm{J}^{2}\left(\mathrm{~K}_{\mathrm{o}}\right)$ is higher than that in the optimal time-inconsistent solution $\mathrm{U}_{2}$, the difference being given by:

$$
\mathrm{J}^{2}\left(\mathrm{~K}_{\mathrm{o}}\right)-\mathrm{U}_{2}=\frac{\delta_{2}}{\left(1-\delta_{2}\right)^{2}}\left\{\ln \left[\frac{\sum_{j=1}^{2}\left[\lambda_{j} \delta_{j} /\left(1-\delta_{j}\right)\right]}{\sum_{j=1}^{2}\left[\lambda_{j} /\left(1-\delta_{j}\right)\right]}\right]-\ln \left(\delta_{2}\right)\right\}>0 .
$$

(iii) Total welfare in the time-consistent solution is lower than that in the optimal timeinconsistent solution as $\sum_{i=1}^{2} \lambda_{i}\left[\mathrm{~J}^{i}\left(\mathrm{~K}_{\mathrm{o}}\right)-\mathrm{U}_{i}\right]<0$.

\section{Recovering the Time Consistent Optimal Solution through a Standard Discounted Optimisation Problem}

The results of Sections II and III showed that the consideration of a temporally consistent solution with heterogenous discounting leads to an inter temporal trade-off that is determined by a weighted average of the discount factors of the agents. This section will provide some basis to such an intuition.

Consider the following benevolent planner program:

$$
\begin{aligned}
& \text { (भ) } \max _{\left\{c_{t}^{i}\right\}} \sum_{t=0}^{+\infty} \Delta_{t} \sum_{i=1}^{n} \lambda_{i} u^{i}\left(c_{t}^{i}\right) \\
& \text { s.t. } \mathrm{K}_{t+1}=\mathrm{F}\left(\mathrm{K}_{t}, 1\right)+(1-\eta) \mathrm{K}_{t}-\sum_{i=1}^{n} c_{t}^{i},
\end{aligned}
$$

$\mathrm{K}_{\mathrm{o}}$ given,

with $\left(\Delta_{t}\right)_{t \in \mathbb{N}}$ a sequence defined by $\Delta_{0}=1$ and $\Delta_{t+1}=\delta_{t} \Delta_{t}$ and $\left(\delta_{t}\right)_{t \in \mathbb{N}}$ a sequence such

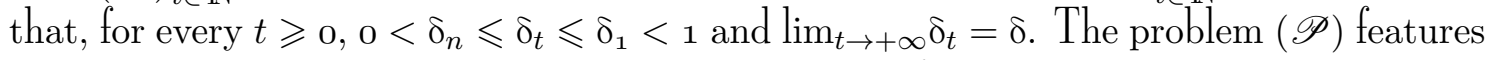
a standard concave planner's problem with a discount factor $\delta_{t}$ that is time-dependent in the vein of Mitra [14]. The following lemma characterizes the solution to this program:

Lemma IV.1.- The optimal solution of the program $(\mathscr{P})$ is characterized by a sequence $\left(c_{t}^{i}, \mathrm{~K}_{t}\right)_{t \in \mathbb{N}}, \mathrm{K}_{\mathrm{o}}$ given, such that, for every $i, j \in\{1, \ldots, n\}$ and for every $t \in \mathbb{N}$ :

(14a) $\lambda_{i} \mathrm{D} u^{i}\left(c_{t}^{i}\right)=\lambda_{j} \mathrm{D} u^{j}\left(c_{t}^{j}\right)$,

(14b) $\mathrm{D} u^{i}\left(c_{t-1}^{i}\right)=\delta_{t-1}\left[\mathrm{D}_{\mathrm{K}} \mathrm{F}\left(\mathrm{K}_{t}, 1\right)+1-\eta\right] \mathrm{D} u^{i}\left(c_{t}^{i}\right)$,

(14c) $\lim _{t \rightarrow+\infty} \Delta_{t} \mathrm{D} u^{i}\left(c_{t}^{i}\right)\left[\mathrm{D}_{\mathrm{K}} \mathrm{F}\left(\mathrm{K}_{t}, 1\right)+1-\eta\right] \mathrm{K}_{t}=\mathrm{o}$,

$\left({ }_{14} \mathrm{~d}\right) \mathrm{K}_{t+1}=\mathrm{F}\left(\mathrm{K}_{t}, 1\right)+(1-\eta) \mathrm{K}_{t}-\sum_{i=1}^{n} c_{t}^{i}$ 
The following proposition establishes that the temporally consistent solution $\left(\mathrm{K}_{t}^{*}, c_{t}^{i *}\right)_{t \in \mathbb{N}, i \in\{1, \ldots, n\}}$ can be recovered as a solution to the planner's program ( $\left.\mathscr{P}\right)$ for a well-chosen sequence of discount factors $\left(\delta_{t}\right)_{t \geqslant 0}$.

Proposition IV.1.- Assume that the sequence $\left(\mathrm{K}_{t}^{*}, c_{t}^{i *}\right)_{t \in \mathbb{N}, i \in\{1,2, \ldots, n\}}$ is a temporally consistent solution of the problem of Section II and that it converges to a non-zero stationary state $\left(\mathrm{K}^{*}, c^{i *}\right)_{i \in\{1,2, \ldots, n\}}$. This sequence is a solution to the problem $(\mathscr{P})$ for a sequence of discount factors $\left(\delta_{t}\right)_{t \in \mathbb{N}}$ such that:

(15) $\delta_{t}=\frac{\mathrm{DW}^{\Delta}\left(\mathrm{K}_{t+1}^{*}\right)}{\mathrm{DW}\left(\mathrm{K}_{t+1}^{*}\right)}$.

Proposition IV.1 establishes how it is possible to recover the temporally consistent solution as a solution to a standard planner's program whose discount factor would correspond to a weighted average of the discount factors of the different agents:

$$
\begin{aligned}
\delta_{t} & =\frac{\mathrm{DW}^{\Delta}\left(\mathrm{K}_{t}^{*}\right)}{\mathrm{DW}\left(\mathrm{K}_{t}^{*}\right)} \\
& =\sum_{i=1}^{n} \delta_{i}\left[\frac{\lambda_{i} \mathrm{DJ}^{i}\left(\mathrm{~K}_{t+1}^{*}\right)}{\sum_{j=1}^{n} \lambda_{j} \mathrm{DJ}^{j}\left(\mathrm{~K}_{t+1}^{*}\right)}\right],
\end{aligned}
$$

where it is noticed that the weighting coefficients $\lambda_{i} \mathrm{DJ}^{i}\left(\mathrm{~K}_{t+1}^{*}\right) / \sum_{j=1}^{n} \lambda_{j} \mathrm{DJ} \mathrm{J}^{j}\left(\mathrm{~K}_{t+1}^{*}\right)$ are time-dependent in the general case.

However, as a special case and for the examples of Sections III.1 and III.2, the functions $\mathrm{DJ}^{i}\left(\mathrm{~K}_{t}\right)$ being homogeneous, this results in a value for the coefficient $\delta_{t}$ of Proposition IV.1 that simplifies to a constant value $\delta$. Within such a configuration, it is further possible to prove that the value function of the program $(\mathscr{P})$ is the function $\mathrm{W}\left(\mathrm{K}_{t}\right)$ up to a constant.

Corollary IV.1.- In the framework of Example III.1, the discount factor of the social planner is given by:

$$
\delta=\sum_{i=1}^{2} \delta_{i} \frac{\lambda_{i} /\left(1-\alpha \delta_{i}\right)}{\sum_{j=1}^{2}\left[\lambda_{j} /\left(1-\alpha \delta_{j}\right)\right]} .
$$

Moreover, the value function of the social planner $(\mathscr{P})$ is given by

$$
\sum_{i=1}^{2} \frac{\alpha \lambda_{i}}{1-\alpha \delta_{i}} \ln \left(\mathrm{K}_{t}\right)+b
$$

This result illustrates how, in the specific case of Example III.1, the planner's problem $(\mathscr{P})$ leads to a value function that is just given by $\mathrm{W}\left(\mathrm{K}_{t}\right)$. This $(\mathscr{P})$ program corresponds to the one solved by a social planner that would explicitly incorporate into its decision criterion a weighted average of the discount factors of the two agents.

\section{Decentralizing the Time-Consistent Optimal Solution}

This final section proves that the temporally consistent solution of the previous sections can be decentralized, and thus recovered as an equilibrium. This requires three different 
elements: distortionary taxation on the capital stock that is particular to each individual; the issuance of public debt; and a system of initial wealths transfers between individuals. Let $\mathrm{X}_{t}^{i}, i \in\{1,2, \ldots, n\}, t \in \mathbb{N}$, denote the individual taxation coefficient on the capital stock, i.e., the fraction of capital and the interest on capital that are left to agent $i$. The agent is thus subsidized for $X_{t}^{i}>1$ but taxed for $X_{t}^{i}<1$. The amount of debt issued at $t \in \mathbb{N}$ is denoted by $b_{t}, a_{t}^{i}$ represents the wealth held at the end of period $t-1$ by agent $i \in\{1,2, \ldots, n\}$, and $\mathrm{T}_{\mathrm{o}}^{i}$ denotes the initial wealth transfers for this agent.

At the initial date $t=0$, any individual $i \in\{1,2, \ldots, n\}$ possesses wealth $a_{i}^{o}$ and it is assumed that all agents hold the total amount of the capital stock so that $\mathrm{K}_{\mathrm{o}}=\sum_{i=1}^{n} a_{\mathrm{o}}^{i}$. After transfers, the wealth of $i$ changes to $a_{i}^{\mathrm{o}}+\mathrm{T}_{\mathrm{o}}^{i}$, with all agents holding the capital stock $\mathrm{K}_{\mathrm{o}}$ and the initial debt $b_{\mathrm{o}}$. Last, $w_{t}$ and $\mathrm{R}_{t}$ denote the competitive values of the wage and interest rates at date $t \in \mathbb{N}$. A competitive equilibrium with capital taxation, initial wealth transfers and debt is then defined in the following statement:

Definition V.1. - An equilibrium is characterized by a sequence

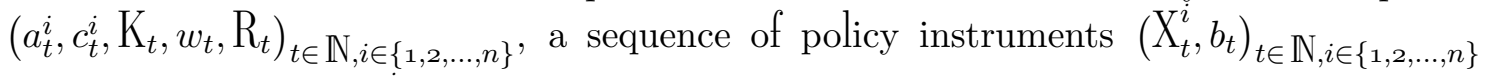
and initial transfers $\left(\mathrm{T}_{\mathrm{o}}^{i}\right)_{i \in\{1,2, \ldots, n\}}$ such that, for any $t \in \mathbb{N}$ and for any $i \in\{1,2, \ldots, n\}$ :

(16a) $\mathrm{D} u^{i}\left(c_{t}^{i}\right) \mathrm{R}_{t} \mathrm{X}_{t}^{i} \delta_{i}=\mathrm{D} u^{i}\left(c_{t-1}^{i}\right)$,

(16b) $a_{t+1}^{i}=\mathrm{R}_{t} \mathrm{X}_{t}^{i} a_{t}^{i}+w_{t}-c_{t}^{i}$

(16c) $a_{1}^{i}=\mathrm{R}_{\mathrm{o}} \mathrm{X}_{\mathrm{o}}^{i}\left(a_{\mathrm{o}}^{i}+\mathrm{T}_{\mathrm{o}}^{i}\right)+w_{\mathrm{o}}-c_{\mathrm{o}}^{i}$

(16d) $\sum_{t=0}^{+\infty}\left[c_{t}^{i} / \prod_{\tau=0}^{t}\left(\mathrm{R}_{\tau} \mathrm{X}_{\tau}^{i}\right)\right]=a_{\mathrm{o}}^{i}+\mathrm{T}_{\mathrm{o}}^{i}+\sum_{t=0}^{+\infty}\left[w_{t} / \prod_{\tau=0}^{t}\left(\mathrm{R}_{\tau} \mathrm{X}_{\tau}^{i}\right)\right]$,

(16e) $b_{\mathrm{o}}=\sum_{i=1}^{n} \mathrm{~T}_{\mathrm{o}}^{i}$

(16f) $b_{t+1}=\mathrm{R}_{t} b_{t}-\mathrm{R}_{t} \sum_{i=1}^{n}\left(1-\mathrm{X}_{t}^{i}\right) a_{t}^{i}$,

$(16 \mathrm{~g}) b_{1}=\mathrm{R}_{\mathrm{o}} b_{\mathrm{o}}-\mathrm{R}_{\mathrm{o}} \sum_{i=1}^{n}\left(1-\mathrm{X}_{\mathrm{o}}^{i}\right)\left(a_{\mathrm{o}}^{i}+\mathrm{T}_{\mathrm{o}}^{i}\right), t \geqslant 1$,

(16h) $\mathrm{K}_{t+1}=\mathrm{F}\left(\mathrm{K}_{t}, 1\right)+(1-\eta) \mathrm{K}_{t}-\sum_{i=1}^{n} c_{t}^{i}, t \geqslant 1$

(16i) $\sum_{i=1}^{n} a_{t}^{i}=\mathrm{K}_{t}+b_{t}, t \geqslant 1$,

(16j) $\sum_{i=1}^{n}\left(a_{\mathrm{o}}^{i}+\mathrm{T}_{\mathrm{o}}^{i}\right)=\mathrm{K}_{\mathrm{o}}+b_{\mathrm{o}}$

$(16 \mathrm{k}) w_{t}=(1 / n) \mathrm{D}_{\mathrm{L}} \mathrm{F}\left(\mathrm{K}_{t}, 1\right)$ and $\mathrm{R}_{t}=\mathrm{D}_{\mathrm{K}} \mathrm{F}\left(\mathrm{K}_{t}, 1\right)+1-\eta$.

with $\mathrm{K}_{\mathrm{o}}, a_{\mathrm{o}}^{i}, i \in\{1,2, \ldots, n\}$ given such that $\mathrm{K}_{\mathrm{o}}=\sum_{i=1}^{n} a_{\mathrm{o}}^{i}$.

In the above definition, $(16 \mathrm{a})$ is the Euler equation, $(16 \mathrm{~b})$ the instantaneous budget constraint of agent $i \in\{1,2, \ldots, n\}$ and $(16 \mathrm{c})$ this same constraint at the initial period $t=0$. Equation $(16 \mathrm{~d})$ is the inter-temporal budget constraint, including the initial wealth transfer and the tax on capital. Equation (16e) is the initial value of the debt corresponding to the 
sum of the transfers, while equation (16f) depicts the budget constraint of the government at date $t$ and $(16 \mathrm{~g})$ this same constraint at the initial date $t=0$. Equation (16h) represents the equilibrium of the goods market at date $t \in \mathbb{N}$, equation (16i) the equilibrium on the capital market at the same date, and equation $(16 \mathrm{j})$ this capital market equilibrium at the initial date. Finally, equation $(16 \mathrm{k})$ defines the equilibrium wage rate -henceforth $w(\mathrm{~K})$ - and the equilibrium return on the capital stock-henceforth $\mathrm{R}(\mathrm{K})$. As usual, one of the defining relationships of the equilibrium is redundant: for example, equation (16h) comes from the recombination of the other relationships.

Letting then $\left(\mathrm{K}_{t}^{*}, c_{t}^{i *}\right)_{t \in \mathbb{N}, i \in\{1,2, \ldots, n\}}$ denote the optimal temporally-consistent solution, the following statement holds:

Proposition V.1.- Consider the equilibrium of Definition IV.1.

(i) The temporally-consistent solution $\left(\mathrm{K}_{t}^{*}, c_{t}^{i *}\right)_{t \in \mathbb{N}, i \in\{1,2, \ldots, n\}}$ can be decentralized through the policy instruments as

$$
\begin{aligned}
& \text { (17a) } \mathrm{X}_{t}^{i}=\frac{1}{\delta_{i}} \frac{\mathrm{DW}^{\Delta}\left(\mathrm{K}_{t}^{*}\right)}{\mathrm{DW}\left(\mathrm{K}_{t}^{*}\right)} \\
& (17 \mathrm{~b}) \mathrm{T}_{\mathrm{o}}^{i}=\sum_{t=0}^{+\infty} \frac{c_{t}^{i *}}{\prod_{\tau=0}^{t}\left[\mathrm{R}\left(\mathrm{K}_{\tau}^{*}\right) \mathrm{X}_{\tau}^{i}\right]}-a_{\mathrm{o}}^{i}-\sum_{t=0}^{+\infty} \frac{w\left(\mathrm{~K}_{t}^{*}\right)}{\prod_{\tau=\mathrm{o}}^{t}\left[\mathrm{R}\left(\mathrm{K}_{\tau}^{*}\right) \mathrm{X}_{\tau}^{i}\right]} \\
& \left({ }_{17 \mathrm{c})} b_{\mathrm{o}}=\sum_{i=1}^{n} \mathrm{~T}_{\mathrm{o}}^{i},\right. \\
& \text { (17d) } b_{1}=\mathrm{R}\left(\mathrm{K}_{\mathrm{o}}^{*}\right) b_{\mathrm{o}}-\mathrm{R}\left(\mathrm{K}_{\mathrm{o}}^{*}\right) \sum_{i=1}^{n}\left(1-\mathrm{X}_{\mathrm{o}}^{i}\right)\left(a_{\mathrm{o}}^{i}+\mathrm{T}_{\mathrm{o}}^{i}\right) .
\end{aligned}
$$

For $t \geqslant 1$, the sequence $\left\{b_{t}\right\}$ is defined by

$$
\text { (18) } b_{t+1}=\mathrm{R}\left(\mathrm{K}_{t}^{*}\right) b_{t}-\mathrm{R}\left(\mathrm{K}_{t}^{*}\right) \sum_{i=1}^{n}\left(1-\mathrm{X}_{t}^{i}\right) a_{t}^{i}
$$

for the sequence $\left\{a_{t}^{i}\right\}$ that is recursively defined through:

$$
\begin{aligned}
& \text { (19a) } \quad a_{1}^{i}=\mathrm{R}\left(\mathrm{K}_{\mathrm{o}}^{*}\right) \mathrm{X}_{\mathrm{o}}^{i}\left(a_{\mathrm{o}}^{i}+\mathrm{T}_{\mathrm{o}}^{i}\right)+w\left(\mathrm{~K}_{\mathrm{o}}^{*}\right)-c_{\mathrm{o}}^{i *}, \\
& (19 \mathrm{~b}) a_{t+1}^{i}=\mathrm{R}\left(\mathrm{K}_{t}^{*}\right) \mathrm{X}_{t}^{i} a_{t}^{i}+w\left(\mathrm{~K}_{t}^{*}\right)-c_{t}^{i *}, t \geqslant 1 .
\end{aligned}
$$

(ii) At the long-run stationary state, the most patient agent will be taxed and the most impatient agent will be subsidized according to $\mathrm{X}^{1}<1$ and $\mathrm{X}^{2}>1$.

The selection of the taxation parameters $X_{t}^{i}$ on the capital stock ensures that the marginal rate of substitution of agent $i$ between periods $t-1$ and $t$ corresponds to the optimal ratio between these two periods:

$$
\forall i \in\{1,2, \ldots, n\}, \frac{\mathrm{D} u^{i}\left(c_{t}^{i *}\right)}{\mathrm{D} u^{i}\left(c_{t-1}^{i *}\right)}=\frac{\mathrm{DW}^{\Delta}\left(\mathrm{K}_{t+1}^{*}\right)}{\mathrm{DW}^{\Delta}\left(\mathrm{K}_{t}^{*}\right)} .
$$

The initial transfers defined by $(17 \mathrm{~b})$ allow the agents to finance their optimal consumption trajectory $\left(c_{t}^{i *}\right)$ over their lifespan. The debt defined in $\left({ }_{17} \mathrm{c}\right)$ and $\left({ }_{17} \mathrm{~d}\right)$ in turn allows the financing of such transfers in a distortionary taxation environment. 
It is worth mentioning that the amount of tax/subsidy $X_{t}^{i}$ that is defined by $(17 \mathrm{a})$ does generally depend upon time. However, this is not any longer the case in the examples analysed by sections III. 1 and III.2 and that lead to homogeneous formulations for $\mathrm{DW}^{\Delta}\left(\mathrm{K}_{t}^{*}\right)$ and DW $\left(\mathrm{K}_{t}^{*}\right)$. More explicitly and in Example III.1, it is obtained that

$$
\mathrm{X}_{t}^{i}=\mathrm{X}^{i}=\frac{1}{\delta_{i}} \frac{\sum_{j=1}^{2} \lambda_{j} \delta_{j} /\left(1-\alpha \delta_{j}\right)}{\sum_{j=1}^{2} \lambda_{j} /\left(1-\alpha \delta_{j}\right)} .
$$

Further, and for the special case where agents have the same instantaneous utility and where the social planner puts equal weights on the agents, it is possible to recover the temporally-consistent stationary state through a system of non-linear taxes and transfers on the capital stock. In this case, all agents benefit from the same amount of consumption $c^{*}$ at the steady state. Their wealth is then given by $(16 \mathrm{~b})$ :

$$
a^{i}=\frac{c^{*}-w\left(\mathrm{~K}^{*}\right)}{\mathrm{R}\left(\mathrm{K}^{*}\right) \mathrm{X}^{i}-1} .
$$

Further noting that $(16 \mathrm{a})$ implies that $\mathrm{R}\left(\mathrm{K}^{*}\right) \mathrm{X}^{i}=1 / \delta_{i}$, we finally obtain that:

$$
a^{i}=\frac{c^{*}-w\left(\mathrm{~K}^{*}\right)}{1 / \delta_{i}-1}
$$

from which it follows that:

$$
a^{1}>a^{2}>\cdots>a^{n} .
$$

In other words, it is possible to decentralize the optimum via a nonlinear system of taxes and transfers on the capital stock.

\section{References}

11 Becker, R. Comparative Dynamics in Aggregate Models of Optimal Capital Accumulation. Quarterly Journal of Economics 1235-1256, 1985 .

[2] Becker, R. Optimal Growth with Heterogeneous Agents and the Twisted Turnpike: An Example. International Journal of Economic Theory, The International Society for Economic Theory 8: 27-47, 2012.

[3] Becker, R. \& C. Foias Strategic Ramsey equilibrium dynamics. Journal of Mathematical Economics 43: 318-346, 2007.

[4] Bewley, T. An Integration of Equilibrium Theory and Turnpike Theory. Journal of Mathematical Economics 10: 233-267, 1982.

[5] Becker, R. \& I. Zilcha Stationary Ramsey Equilibria under Uncertainty. Journal of Economic Theory 75: 122-140, 1997.

[6] Epstein, L. The Global Stability of Efficient Intertemporal Allocations. Econometrica 55: 329-55, 1987. 
7] Epstein, L. A Simple Dynamic General Equilibrium Model. Journal of Economic Theory 41: 68-95, 1987.

[8] Coles, J. Equilibrium Turnpike Theory with Constant Returns to Scale and Possible Heterogeneous Discount Factors. International Economic Review 26: 671-79, 1985.

[9] Coles, J. Equilibrium Turnpike Theory with Time-Separable Utility. Journal of Economic Dynamics and Control 10: 367-394, 1986.

[10] Harris, C. \& D. Laibson Dynamic Choices of Hyperbolic Consumers. Econometrica 69: 935-957, 2001.

[11] Judd, K. Existence, Uniqueness, and Computational Theory for Time Consistent Equilibria: A Hyperbolic Discounting Example. Mimeograph, 2004.

[12] Krussel, P. \& A. Smith Consumption-Savings Decisions with Quasi-Geometric Discounting. Econometrica 71: 365-375, 2003.

[13] Le VAn, C. \& Y. Vailakis Existence of a Competitive Equilibrium in a One Sector Growth Model with Heterogeneous Agents and Irreversible Investment. Economic Theory 22: 743-771, 2003 .

[14] Mitra, T. On Optimal Growth with Variable Discount Rates: Existence and Stability Results. International Economic Review 20: 133-145, 1979.

[15] Mitra, T. \& G. Sorger On Ramsey's Conjecture. Journal of Economic Theory 148: 1953-1973, 2013 .

[16] Phelps, E.S. \& R.A. Pollack On Second-Best National Saving and GameEquilibrium Growth. Review of Economic Studies 35: 185-199, 1968.

[17] Ramsey, F. A Mathematical Theory of Savings. Economic Journal 38: 543-549, 1928.

[18] Sorger, G. On the Long-Run Distribution of Capital in the Ramsey Model. Journal of Economic Theory 105: 226-243, 2002.

[19] Strotz, R. Myopia and Dynamic Inconsistency in Preferences. Review of Economic Studies 23: 165-180, 1955 .

\section{Proofs}

\section{VI.1 Proof of Lemma II.1}

Proof: The consumption policy functions are implicitly defined through:

$$
\lambda_{i} \mathrm{D} u^{i}\left[\vartheta_{\mathrm{C}}^{i}\left(\mathrm{~K}_{t}\right)\right]=\mathrm{DW}^{\Delta}\left[\mathrm{F}\left(\mathrm{K}_{t}, 1\right)+(1-\eta) \mathrm{K}_{t}-\sum_{i=1}^{n} \vartheta_{\mathrm{C}}^{i}\left(\mathrm{~K}_{t}\right)\right] .
$$

All of the functions $\mathrm{D} u^{i}(\cdot)$ and $\mathrm{DW}^{\Delta}(\cdot)$ being however of class $\mathcal{C}^{1}, \vartheta_{\mathrm{C}}^{i}\left(\mathrm{~K}_{t}\right)$ has this same property. Further differentiating with respect to $K_{t}$, produces:

$$
\text { (A.1) } \lambda_{i} \mathrm{D} \vartheta_{\mathrm{C}}^{i}\left(\mathrm{~K}_{t}\right) \mathrm{D}^{2} u^{i}\left[\vartheta_{\mathrm{C}}^{i}\left(\mathrm{~K}_{t}\right)\right]=\mathrm{D}^{2} \mathrm{~W}^{\Delta}\left[\vartheta_{\mathrm{K}}\left(\mathrm{K}_{t}\right)\right]\left[\mathrm{D}_{\mathrm{K}} \mathrm{F}\left(\mathrm{K}_{t}, 1\right)+(1-\eta)-\sum_{i=1}^{n} \mathrm{D} \vartheta_{\mathrm{C}}^{i}\left(\mathrm{~K}_{t}\right)\right] \text {. }
$$


Simplifying the notation as:

$$
\begin{aligned}
& \chi^{i}=\mathrm{D} \vartheta_{\mathrm{C}}^{i}\left(\mathrm{~K}_{t}\right), \\
& \beta^{i}=\lambda_{i} \frac{\mathrm{D}^{2} u^{i}\left[\vartheta_{\mathrm{C}}^{i}\left(\mathrm{~K}_{t}\right)\right]}{\mathrm{D}^{2} \mathrm{~W}^{\Delta}\left[\vartheta_{\mathrm{K}}\left(\mathrm{K}_{t}\right)\right]}>0, \\
& \zeta=\mathrm{D}_{\mathrm{K}} \mathrm{F}\left(\mathrm{K}_{t}, 1\right)+(1-\eta)>0,
\end{aligned}
$$

the preceding equation (A.1) is

$$
\text { (A.2) } \chi^{i}=\zeta / \beta^{i}-1 / \beta^{i} \sum_{j=1}^{n} \chi^{j}
$$

Summing over $i$ :

$$
\sum_{i=1}^{n} \chi^{i}\left(1+\sum_{i=1}^{n} \frac{1}{\beta^{i}}\right)=\zeta \sum_{i=1}^{n} \frac{1}{\beta^{i}} .
$$

Finally:

$$
\sum_{i=1}^{n} \chi^{i}=\frac{\zeta \sum_{i=1}^{n}\left(1 / \beta^{i}\right)}{1+\sum_{i=1}^{n}\left(1 / \beta^{i}\right)}
$$

Integrating into (A.2), it is obtained that:

$$
\begin{aligned}
\beta^{i} \chi^{i} & =\zeta-\frac{\zeta \sum_{i=1}^{n}\left(1 / \beta^{i}\right)}{1+\sum_{i=1}^{n}\left(1 / \beta^{i}\right)} \\
& =\frac{\zeta}{1+\sum_{i=1}^{n}\left(1 / \beta^{i}\right)} .
\end{aligned}
$$

The inequality $\chi^{i}>0$ will then always hold, as $\zeta>0$ and, from the concavity assumptions, $\beta_{i}>$ o for any $i \in\{1,2, \ldots, n\}$. From equation (A.1), it can then be seen that $\mathrm{D} \vartheta_{\mathrm{K}}\left(\mathrm{K}_{t}\right)>0$. Q.E.D

\section{VI.2 Proof of Proposition II.1}

Proof: (i) The envelope condition (13c) together with the expressions for $\mathrm{DW}^{\Delta}(\mathrm{K})$ and $\mathrm{DW}(\mathrm{K})$ in $\left({ }_{13} \mathrm{f}\right)$ and $(13 \mathrm{e})$ produce, making use of $(13 \mathrm{~d})$ and $\left({ }_{13 \mathrm{~g}}\right)$, a generalized definition of the long-run stationary value of the capital stock:

$$
\begin{aligned}
\left\{\sum_{i=1}^{n} \frac{\lambda_{i} \delta_{i} \mathrm{D} u^{i}\left[\vartheta_{\mathrm{C}}^{i}(\mathrm{~K})\right]}{1-\delta_{i}\left[\mathrm{D}_{\mathrm{K}} \mathrm{F}(\mathrm{K}, 1)+1-\eta\right.}-\sum_{j=1}^{n}(\mathrm{~K})\right. & \left.\mathrm{D}_{\mathrm{C}}^{j}(\mathrm{~K})\right] \\
= & \left\{\sum_{i=1}^{n} \frac{\left.\mathrm{D}_{\mathrm{K}} \mathrm{F}(\mathrm{K}, 1)+(1-\eta)\right]}{1-\delta_{i}\left[\mathrm{D}_{\mathrm{K}} \mathrm{F}(\mathrm{K}, 1)+1-\eta-\sum_{j=1}^{n}\left[\vartheta_{\mathrm{C}}^{i}(\mathrm{~K})\right] \mathrm{D} \vartheta_{\mathrm{C}}^{i}(\mathrm{~K})\right]}\right\} .
\end{aligned}
$$

However, taking advantage of the fact that, for any $i \in\{1, \ldots, n\}, \lambda_{i} \mathrm{D} u^{i}\left[C^{i}(\mathrm{~K})\right]=$ $\mathrm{DW}^{\Delta}(\mathrm{K})$, the above expression may be simplified as:

$$
\begin{aligned}
(\mathrm{A} .3)\left\{\sum_{i=1}^{n} \frac{\delta_{i} \mathrm{D} \vartheta_{\mathrm{C}}^{i}(\mathrm{~K})}{1-\delta_{i}\left[\mathrm{D}_{\mathrm{K}} \mathrm{F}(\mathrm{K}, 1)+1-\eta-\sum_{j=1}^{n} \mathrm{D} \vartheta_{\mathrm{C}}^{j}(\mathrm{~K})\right]}\right\}\left[\mathrm{D}_{\mathrm{K}} \mathrm{F}(\mathrm{K}, 1)+(1-\eta)\right] \\
=\left\{\sum_{i=1}^{n} \frac{\mathrm{D} \vartheta_{\mathrm{C}}^{i}(\mathrm{~K})}{1-\delta_{i}\left[\mathrm{D}_{\mathrm{K}} \mathrm{F}(\mathrm{K}, 1)+1-\eta-\sum_{j=1}^{n} \mathrm{D} \vartheta_{\mathrm{C}}^{j}(\mathrm{~K})\right]}\right\} .
\end{aligned}
$$


We then have a generalized modified golden rule in which all of the discount factors come into play.

(ii) It however remains to show that this expression defines a value of $\zeta:=\mathrm{D}_{\mathrm{K}} \mathrm{F}(\mathrm{K}, 1)+1-\eta$ such that $\zeta \in] 1 / \delta_{1}, 1 / \delta_{n}[$. Equation (A.3) may be restated in an implicit form $\mathrm{H}(\zeta)=0$ :

$$
\mathrm{H}(\zeta):=\sum_{i=1}^{n} \frac{\left(\zeta-1 / \delta_{i}\right) \delta_{i} \mathrm{D} \vartheta_{\mathrm{C}}^{i}(\mathrm{~K})}{1-\delta_{i}\left[\zeta-\sum_{i=1}^{n} \mathrm{D} \vartheta_{\mathrm{C}}^{i}(\mathrm{~K})\right]}
$$

Lemma II.1 establishes that, for any $i \in\{1, \ldots, n\}, \mathrm{D} \vartheta_{\mathrm{C}}^{i}(\mathrm{~K})>0$, hence: $\sum_{i=1}^{n} \mathrm{D} \vartheta_{\mathrm{C}}^{i}(\mathrm{~K})>0$. The denominator of the elements of the sum on the R.H.S. of the expression for $\mathrm{H}(\zeta)$ is positive since it comes from that in $(13 \mathrm{~d})$, and $\mathrm{DJ}^{i}(\mathrm{~K})>\mathrm{o}$ for any $i \in\{1,2, \ldots, n\}$. Hence, and for any $i \in\{1,2, \ldots, n\}$,

$$
1-\delta_{i}\left[\zeta-\sum_{j=1}^{n} \mathrm{D} \vartheta_{\mathrm{C}}^{j}(\mathrm{~K})\right]>0
$$

or

$$
\zeta<\sum_{j=1}^{n} \mathrm{D} \vartheta_{\mathrm{C}}^{j}(\mathrm{~K})+\frac{1}{\delta_{i}}
$$

the only relevant constraint being the most restrictive one, i.e.:

$$
\zeta<\sum_{j=1}^{n} \mathrm{D} \vartheta_{\mathrm{C}}^{j}(\mathrm{~K})+\frac{1}{\delta_{1}}
$$

Taking as given the values of $\mathrm{D} \vartheta_{\mathrm{C}}^{i}, i \in\{1,2\}$, the function $\mathrm{H}(\zeta)$ is monotonic increasing. It can further be noted that, for $\zeta=1 / \delta_{1}$, we have $\mathrm{H}\left(1 / \delta_{1}\right)<0, \zeta$ thus needing to be greater than $1 / \delta_{1}$.

On the contrary, for $\zeta=1 / \delta_{n}$, two separate configurations may arise and are considered separately.

$\mathrm{a} / 1 / \delta_{n}<\sum_{i=1}^{n} \mathrm{D} \vartheta_{\mathrm{C}}^{i}(\mathrm{~K})+1 / \delta_{1}$ : here $\mathrm{H}\left(1 / \delta_{n}\right)>\mathrm{o}$ and the existence and uniqueness of a $\zeta \in] 1 / \delta_{1}, 1 / \delta_{n}[$ such that $\mathrm{H}(\zeta)=$ o both hold;

$\mathrm{b} / 1 / \delta_{n}>\sum_{i=1}^{n} \mathrm{D} \vartheta_{\mathrm{C}}^{i}(\mathrm{~K})+1 / \delta_{1}$ : letting then $\zeta_{\mathrm{o}}=\sum_{i=1}^{n} \mathrm{D} \vartheta_{\mathrm{C}}^{i}(\mathrm{~K})+1 / \delta_{1}$, with $\zeta_{\mathrm{o}}<1 / \delta_{n}$, as $\lim _{\zeta \rightarrow \zeta_{0}^{-}} \rightarrow+\infty$, there then exists a value $\left.\zeta \in\right] 1 / \delta_{1}, \zeta_{0}[$ such that $H(\zeta)=0$.

The existence argument for $\mathrm{H}(\zeta)=$ o thus holds for the entire interval of values for $\delta_{i}$, which of the result.

Q.E.D.

\section{VI.3 Proof of Proposition III.1}

Proof: (i) The payoff functions for the two individuals are conjectured to have the following form:

$$
\mathrm{J}^{i}(\mathrm{~K})=a_{i} \ln (\mathrm{K})+b_{i},
$$

for $a_{i}>$ o. The decision rules for the two individuals are the solutions of the following program:

$$
\mathrm{W}\left(\mathrm{K}_{t}\right)=\max _{\left\{c_{t}^{i}\right\}}\left\{\sum_{i=1}^{2} \lambda_{i} \ln \left(c_{t}^{i}\right)+\sum_{i=1}^{2} \lambda_{i} \delta_{i} a_{i} \ln \left(\mathrm{K}_{t+1}\right) \quad \text { s.t. } \quad \mathrm{K}_{t+1}=\mathrm{A}\left(\mathrm{K}_{t}\right)^{\alpha}-\sum_{i=1}^{2} c_{t}^{i} \cdot\right\}
$$


The first-order conditions are then:

$$
\frac{\lambda_{i}}{c_{t}^{i}}=\frac{\sum_{i=1}^{2} \lambda_{i} \delta_{i} a_{i}}{\mathrm{~A}\left(\mathrm{~K}_{t}\right)^{\alpha}-\sum_{i=1}^{2} c_{t}^{i}}, \quad i \in\{1,2\} .
$$

(ii) These two equations in turn allow the consumption decision rules to be derived as:

$$
\begin{aligned}
& c_{t}^{i}=\frac{\lambda_{i} \mathrm{~A}\left(\mathrm{~K}_{t}\right)^{\alpha}}{1+\mu}, \\
& \text { with } \mu=\sum_{i=2} \lambda_{i} \delta_{i} a_{i},
\end{aligned}
$$

from which we have the investment decision rule:

$$
\mathrm{K}_{t+1}=\mathrm{A}\left(\mathrm{K}_{t}\right)^{\alpha} \frac{\mu}{1+\mu} \text {. }
$$

These decision rules allow us to calculate the payoff functions $\mathrm{J}^{1}$ and $\mathrm{J}^{2}$ for the individual agents:

$$
\begin{aligned}
J^{i}\left(\mathrm{~K}_{t}\right) & =\sum_{\tau=0}^{+\infty}\left(\delta_{i}\right)^{\tau} \ln \left(c_{t+\tau}^{i}\right) \\
& =\sum_{\tau=0}^{+\infty}\left[\left(\delta_{i}\right)^{\tau} \alpha \ln \left(\mathrm{K}_{t+\tau}\right)+\left(\delta_{i}\right)^{\tau} \ln \left(\frac{\lambda_{i} \mathrm{~A}}{1+\mu}\right)\right] .
\end{aligned}
$$

Letting $\chi_{t}:=\ln \left(\mathrm{K}_{t}\right)$, from the decision rule for investment, it is derived that:

$$
\chi_{t+\tau+1}=\alpha \chi_{t+\tau}+\ln \left(\frac{A \mu}{1+\mu}\right) \text {. }
$$

So

$$
J^{1}\left(K_{t}\right)=\alpha \chi_{t}+\delta_{1} \alpha^{2} \chi_{t}+\left(\delta_{1}\right)^{2} \alpha^{3} \chi_{t}+\ldots+b_{1},
$$

for $b_{i}$ some constant parameter. Finally:

$$
\begin{aligned}
J^{i}\left(K_{t}\right) & =\alpha \chi_{t} \sum_{\tau=0}^{+\infty}\left(\alpha \delta_{i}\right)^{\tau}+b_{i} \\
& =\frac{\alpha}{1-\alpha \delta_{i}} \ln \left(K_{t}\right)+b_{i} .
\end{aligned}
$$

We then have:

$$
\begin{aligned}
& a_{i}=\frac{\alpha}{1-\alpha \delta_{i}}, \\
& \mu=\sum_{i=1}^{2} \lambda_{i} \delta_{i} \frac{\alpha}{1-\alpha \delta_{i}} .
\end{aligned}
$$

(iii) Contrary to the results in Le Van \& Vailakis [13] and Becker [2], $\mathrm{K}_{t}$ as described by the investment decision rule is monotonic and converges to a value $K$ such that

$$
\mathrm{K}^{1-\alpha}=\frac{A \mu}{1+\mu}
$$

or, rearranging:

$$
\mathrm{AK}^{\alpha-1}=\frac{1+\sum_{i=1}^{2} \lambda_{i} \alpha \delta_{i} /\left(1-\alpha \delta_{i}\right)}{\sum_{i=1}^{2} \lambda_{i} \alpha \delta_{i} /\left(1-\alpha \delta_{i}\right)}
$$

Finally, this can be expressed as:

$$
\mathrm{AK}^{\alpha-1}=\frac{\sum_{i=1}^{2} \lambda_{i} /\left(1-\alpha \delta_{i}\right)}{\sum_{i=1}^{2} \lambda_{i} \alpha \delta_{i} /\left(1-\alpha \delta_{i}\right)}
$$

completing the statement. 


\section{VI.4 Proof of Proposition III.2}

Proof: (i)-(ii) In order for the objectives of the two agents to remain bounded, it is further assumed that:

(A.4) $\sup \left(\delta_{1} \mathrm{~A}^{(\varsigma-1) / \varsigma}, \delta_{2} \mathrm{~A}^{(\varsigma-1) / \varsigma}\right)=\delta_{1} \mathrm{~A}^{(\varsigma-1) / \varsigma}<1$.

The payoff functions for the two individuals are then assumed to take the following shape:

$$
\mathrm{J}^{i}(\mathrm{~K})=a_{i} \frac{(\mathrm{K})^{1-1 / \varsigma}}{1-1 / \varsigma}, i \in\{1,2\}
$$

for $a_{i}>$ o. The decision rules for the two individuals are the solutions to the following program:

$$
\mathrm{W}\left(\mathrm{K}_{t}\right)=\max _{\left\{c_{t}^{i}\right\}}\left\{\lambda_{i} \frac{\left(c_{t}^{i}\right)^{1-1 / \varsigma}}{1-1 / \varsigma}+\sum_{i=1}^{2} \lambda_{i} \delta_{i} a_{i} \frac{\left(\mathrm{K}_{t+1}\right)^{(\varsigma-1) / \varsigma}}{(\varsigma-1) / \varsigma} \text { s.t. } \mathrm{K}_{t+1}=\mathrm{AK}_{t}-\sum_{i=1}^{2} c_{t}^{i}\right\} .
$$

The first-order conditions are then:

$$
\lambda_{i}\left(c_{t}^{i}\right)^{-1 / \varsigma}=\sum_{i=1}^{2} \lambda_{i} \delta_{i} a_{i}\left(\mathrm{~K}_{t+1}\right)^{-1 / \varsigma}, i \in\{1,2\} .
$$

Letting $\mu:=\sum_{i=1}^{2} \lambda_{i} \delta_{i} a_{i}$, the two equations in turn allow us to derive the investment and consumption decision rules as:

$$
\begin{aligned}
& \mathrm{K}_{t+1}^{i}=\frac{A K_{t}}{1+\sum_{i=1}^{2}\left(\lambda_{i} / \mu\right)^{\varsigma}}, \\
& c_{t}^{i}=\frac{\left(\lambda_{i} / \mu\right)^{\varsigma} A K_{t}}{1+\sum_{i=1}^{2}\left(\lambda_{i} / \mu\right)^{\varsigma}} .
\end{aligned}
$$

From the above, for $\mathrm{B}(\mu)=1+\sum_{i=1}^{2}\left(\lambda_{i} / \mu\right)^{\varsigma}$ :

$$
\begin{aligned}
\mathrm{K}_{t+\tau} & =\left(\frac{\mathrm{A}}{\mathrm{B}(\mu)}\right)^{\tau} \mathrm{K}_{t} ; \\
c_{t+\tau}^{i} & =\left(\frac{\lambda_{i}}{\mu}\right)^{\varsigma}\left(\frac{\mathrm{A}}{\mathrm{B}(\mu)}\right)^{\tau+1} \mathrm{~K}_{t}, i \in\{1,2\} .
\end{aligned}
$$

The knowledge of the decision rules allows us to calculate the payoff functions $\mathrm{J}^{1}(\cdot)$ and $\mathrm{J}^{2}(\cdot)$ for the individual agents:

$$
\begin{aligned}
J^{i}\left(K_{t}\right) & =\sum_{\tau=0}^{+\infty}\left(\delta_{i}\right)^{\tau} \frac{\left(c_{t+\tau}^{i}\right)^{1-1 / \varsigma}}{1-1 / \varsigma} \\
& =\frac{1}{1-1 / \varsigma}\left(\frac{\lambda_{i}}{\mu}\right)^{\varsigma-1}\left(\mathrm{~K}_{t}\right)^{1-1 / \varsigma}\left(\frac{\mathrm{A}}{\mathrm{B}(\mu)}\right)^{(\varsigma-1) / \varsigma} \sum_{\tau=0}^{+\infty}\left(\delta_{i}\right)^{\tau}\left(\frac{\mathrm{A}}{\mathrm{B}(\mu)}\right)^{\tau(\varsigma-1) / \varsigma}
\end{aligned}
$$

where the convergence of the sum on the R.H.S. requires that

$$
(\mathrm{A} .5) \delta_{i}\left(\frac{\mathrm{A}}{\mathrm{B}(\mu)}\right)^{(\varsigma-1) / \varsigma}<1, i \in\{1,2\}
$$

The payoff of agent $i \in\{1,2\}$ is then:

$$
\mathrm{J}^{i}\left(\mathrm{~K}_{t}\right)=\frac{1}{1-1 / \varsigma}\left(\frac{\lambda_{i}}{\mu}\right)^{\varsigma-1}\left(\mathrm{~K}_{t}\right)^{1-1 / \varsigma}\left(\frac{\mathrm{A}}{\mathrm{B}(\mu)}\right)^{(\varsigma-1) / \varsigma} \frac{1}{1-\delta_{i}(\mathrm{~A} / \mathrm{B}(\mu))^{(\varsigma-1) / \varsigma}} .
$$


Comparing the two terms for $J^{i}\left(K_{t}\right)$, we then have

$$
a_{i}=\left(\frac{\lambda_{i}}{\mu}\right)^{(\varsigma-1) / \varsigma}\left(\frac{\mathrm{A}}{\mathrm{B}(\mu)}\right)^{(\varsigma-1) / \varsigma} \frac{1}{1-\delta_{i}(\mathrm{~A} / \mathrm{B}(\mu))^{(\varsigma-1) / \varsigma}} .
$$

As $\mu=\sum_{i=1}^{2} \lambda^{i} \delta_{i} a_{i}$, the coefficient $\mu$ is implicitly defined as a solution to:

$$
\mu=\sum_{i=1}^{2} \lambda_{i} \delta_{i}\left(\frac{\lambda_{i}}{\mu}\right)^{\varsigma-1} \frac{(\mathrm{A} / \mathrm{B}(\mu))^{(\varsigma-1) / \varsigma}}{1-\delta_{i}(\mathrm{~A} / \mathrm{B}(\mu))^{(\varsigma-1) / \varsigma}},
$$

with $\mathrm{B}(\mu)=1+\sum_{i=1}^{2}\left(\lambda_{i} / \mu\right)^{\varsigma}$. Rearranging, this becomes:

$$
1=\sum_{i=1}^{2}\left(\frac{\lambda_{i}}{\mu}\right)^{\varsigma} \frac{\delta_{i}}{(\mathrm{~B}(\mu) / \mathrm{A})^{(\varsigma-1) / \varsigma}-\delta_{i}} .
$$

Rearranging

$$
\text { (A.6) } \mu^{\varsigma}=\sum_{i=1}^{2}\left(\lambda_{i}\right)^{\varsigma} \frac{\delta_{i}}{(\mathrm{~B}(\mu) / \mathrm{A})^{(\varsigma-1) / \varsigma}-\delta_{i}} .
$$

In order to analyse the $\mu$-solutions of this equation, two separate configurations are then considered according to whether $\varsigma \in] \mathrm{o}, 1[$ or $\varsigma \in] 1,+\infty[$.

$\mathrm{a} / \varsigma \in]_{0}, 1[$. For $\varsigma \in] \mathrm{o}, 1[$, the conditions (A.5) are jointly equivalent to:

$$
\mathrm{B}(\mu)<\inf \left(\delta_{1}^{\varsigma /(\varsigma-1)} \mathrm{A}, \delta_{2}^{\varsigma /(\varsigma-1)} \mathrm{A}\right)=\delta_{1}^{\varsigma /(\varsigma-1)} \mathrm{A},
$$

where $\delta_{1}^{\varsigma /(\varsigma-1)} \mathrm{A}>1$ is derived from equation (A.4). The coefficient $\mathrm{B}(\mu)$ being furthermore a decreasing monotonic function of $\mu$, denoted $\mathrm{B}(\mu)$, that satisfies $\mathrm{B}\left(0^{+}\right)=+\infty$ and $\mathrm{B}(+\infty)=1$, consider a finite value $\left.\bar{\mu}_{1} \in\right]_{0},+\infty\left[\right.$ defined by $\mathrm{B}\left(\bar{\mu}_{1}\right)=\mathrm{A}\left(\delta_{1}\right)^{\varsigma /(\varsigma-1)}$, that in turn yields:

$$
\mathrm{B}(\mu)<\mathrm{A}\left(\delta_{1}\right)^{\varsigma /(\varsigma-1)} \Longleftrightarrow \mu>\bar{\mu}_{1} .
$$

We then require a coefficient $\mu$ that satisfies $\mu>\bar{\mu}_{1}$ and solves equation (A.6), the latter being reformulated as $H_{1}(\mu)=H_{2}(\mu)$. Over the interval $] \bar{\mu}_{1},+\infty\left[, H_{1}(\cdot)\right.$ is monotonically increasing from $\mathrm{H}_{1}\left(\bar{\mu}_{1}\right)$ to $+\infty$. On the contrary, $\mathrm{H}_{2}(\cdot)$ is monotonically decreasing from $+\infty$ to

$$
\sum_{i=1}^{2}\left(\lambda_{i}\right)^{\varsigma} \frac{\delta_{i}}{\mathrm{~A}^{(1-\varsigma) / \varsigma}-\delta_{i}}
$$

from which the existence and uniqueness of $\mu$ results. The existence and uniqueness of $\mu=\sum_{i}^{2} \lambda_{i} \delta_{i} a_{i}$ being established, the expressions of $a_{i}, i \in\{1,2\}$ are

$$
a_{i}=\left(\frac{\lambda_{i}}{\mu}\right)^{(\varsigma-1) / \varsigma}\left(\frac{\mathrm{A}}{\mathrm{B}(\mu)}\right)^{(\varsigma-1) / \varsigma} \frac{1}{1-\delta_{i}(\mathrm{~A} / \mathrm{B}(\mu))^{(\varsigma-1) / \varsigma}} .
$$

$\mathrm{b} / \varsigma \in]_{1},+\infty[$. The conditions (A.5) are jointly equivalent to:

$$
\mathrm{B}(\mu)>\max \left(\delta_{1}^{\varsigma /(\varsigma-1)} \mathrm{A}, \delta_{2}^{\varsigma /(\varsigma-1)} \mathrm{A}\right)=\delta_{1}^{\varsigma /(\varsigma-1)} \mathrm{A},
$$

where $\delta_{1}^{\varsigma /(\varsigma-1)} \mathrm{A}<1$ is derived from equation (A.4). Further noting that the coefficient $B(\mu)$ satisfies $B(\mu)>1$ for any $\mu$, this condition holds everywhere. We can restate equation (A.6) as

$$
1=\sum_{i=1}^{2} \frac{\left(\lambda_{i}\right)^{\varsigma}}{\mu^{\varsigma}} \frac{\delta_{i}}{\left[1+\sum_{i=1}^{2}\left(\lambda_{i} / \mu\right)^{\varsigma}\right]^{(\varsigma-1) / \varsigma}(1 / A)^{(\varsigma-1) / \varsigma}-\delta_{i}}
$$


And then state it as:

$$
1=\sum_{i=1}^{2}\left(\lambda_{i}\right)^{\varsigma} \frac{\delta_{i}}{\mu\left[\mu^{\varsigma}+\sum_{i=1}^{2}\left(\lambda_{i}\right)^{\varsigma}\right]^{(\varsigma-1) / \varsigma}(1 / \mathrm{A})^{(\varsigma-1) / \varsigma}-\delta_{i} \mu^{\varsigma}} .
$$

We then have to prove that the function

(A.7) $f(\mu)=\mu \frac{\left(\mu^{\varsigma}+b\right)^{(\varsigma-1) / \varsigma}}{a}-\delta_{i} \mu^{\varsigma}, \quad i \in\{1,2\}$,

increases in $\mu$, for $b=\sum_{i=1}^{2}\left(\lambda_{i}\right)^{\varsigma}$ and $a=\mathrm{A}^{(\varsigma-1) / \varsigma}$. Its derivative is

$$
\mathrm{D} f(\mu)=\frac{\left(\mu^{\varsigma}+b\right)^{-1 / \varsigma}}{a}\left(\varsigma \mu^{\varsigma}+b\right)-\delta_{i} \varsigma \mu^{\varsigma-1} .
$$

Recalling that, for any $i \in\{1,2\}, \delta_{i} a<1$, we have:

$$
\mathrm{D} f(\mu)>\frac{1}{a}\left[\left(\mu^{\varsigma}+b\right)^{-1 / \varsigma}\left(\varsigma \mu^{\varsigma}+b\right)-\varsigma \mu^{\varsigma-1}\right] \text {. }
$$

We wish to establish that $\left(\mu^{\varsigma}+b\right)^{-1 / \varsigma}\left(\varsigma \mu^{\varsigma}+b\right)-\varsigma \mu^{\varsigma-1}>0$; this is equivalent to:

$$
\varsigma \mu^{\varsigma}+b-\varsigma \mu^{\varsigma-1}\left(\mu^{\varsigma}+b\right)^{1 / \varsigma}>0 .
$$

Letting $\psi(b)=\varsigma \mu^{\varsigma}+b-\varsigma \mu^{\varsigma-1}\left(\mu^{\varsigma}+b\right)^{1 / \varsigma}$, it is readily obtained that $\psi(0)=0$ and $\mathrm{D} \psi(b)=1-\mu^{\varsigma-1}\left(\mu^{\varsigma}+b\right)^{1 / \varsigma-1}$. Noting that $\left(\mu^{\varsigma}+b\right)^{(\varsigma-1) / \varsigma}>\mu^{\varsigma-1}$ results from $\mu^{\varsigma}+b>\mu^{\varsigma}$, we eventually have that $\mathrm{D} \psi(b)>0$ and $\psi(b)>0$ for any $b>0$.

It has hence been established that $f(\cdot)$ increases in $\mu$. The R.H.S. of (A.7) is a monotonic function that falls from $+\infty$ to o as $\mu$ rises from o to $+\infty$, which establishes the existence and uniqueness of $\mu$.

(iii) Consider the following problem:

$$
\max _{\left\{c_{t}^{i}\right\}} \sum_{t=0}^{+\infty} \sum_{i=1}^{2} \lambda_{i}\left(\delta_{i}\right)^{t} \frac{\left(c_{t}^{i}\right)^{1-1 / \varsigma}}{(1-1 / \varsigma)} \quad \text { s.t. } \quad \mathrm{K}_{t+1}=\mathrm{AK}_{t}-\sum_{i=1}^{2} c_{t}^{i}, \mathrm{~K}_{\mathrm{o}} \text { given. }
$$

The dynamic Lagrangean is

$$
\mathrm{L}_{t}=\sum_{i=1}^{2} \lambda_{i}\left(\delta_{i}\right)^{t} \frac{\left(c_{t}^{i}\right)^{1-1 / \varsigma}}{(1-1 / \varsigma)}+\mu_{t+1}\left(\mathrm{AK}_{t}-\sum_{i=1}^{2} c_{t}^{i}\right)-\mu_{t} \mathrm{~K}_{t} .
$$

The necessary and sufficient conditions for an optimal trajectory are:

$$
\begin{aligned}
& \mu_{t}=A \mu_{t+1}, \\
& \lambda_{i}\left(\delta_{i}\right)^{t}\left(c_{t}^{i}\right)^{-1 / \varsigma}=\mu_{t+1}, i \in\{1,2\}, \\
& \mathrm{K}_{t+1}=\mathrm{AK}_{t}-\sum_{i=1}^{2}\left(\lambda_{i}\right)^{\varsigma}\left(\delta_{i}\right)^{\varsigma t} \mu_{t+1}{ }^{-\varsigma}, \\
& \mu_{t+1}=\frac{\mu_{t}}{\mathrm{~A}}, \\
& \lim _{t \rightarrow+\infty} \mu_{t} \mathrm{~K}_{t}=0 .
\end{aligned}
$$

Letting $k_{t}=\mathrm{K}_{t} / \mathrm{A}^{t}$, the last three conditions can be rewritten as:

$$
k_{t+1}=k_{t}-\sum_{i=1}^{2}\left(\lambda_{i}\right)^{\varsigma}\left(\delta_{i}\right)^{\varsigma t} \mathrm{~A}^{(\varsigma-1)(t+1)}\left(\mu_{\mathrm{o}}\right)^{-\varsigma}
$$




$$
\begin{aligned}
& \mu_{t}=\frac{1}{\mathrm{~A}^{t}} \mu_{\mathrm{o}}, \\
& \lim _{t \rightarrow+\infty} k_{t} \mu_{\mathrm{o}}=0 .
\end{aligned}
$$

For a given $\mu_{\mathrm{o}}$, the last equation implies that $\lim _{t \rightarrow+\infty} k_{t} \mu_{\mathrm{o}}=0$. Noting then that $k_{t+1}$ can be rewritten as, after iteration:

$$
k_{t}=\mathrm{K}_{\mathrm{o}}-\left(\mu_{\mathrm{o}}\right)^{-\varsigma} \sum_{\tau=0}^{t-1} \sum_{i=1}^{2}\left(\lambda_{i}\right)^{\varsigma}\left(\delta_{i}\right)^{\varsigma \tau} \mathrm{A}^{(\varsigma-1)(\tau+1)},
$$

taking limits and from $\lim _{t \rightarrow+\infty} k_{t} \mu_{\mathrm{o}}=\mathrm{o}$, we obtain:

$$
\mathrm{K}_{\mathrm{o}}=\left(\mu_{\mathrm{o}}\right)^{-\varsigma} \sum_{\tau=0}^{+\infty} \sum_{i=1}^{2}\left(\lambda_{i}\right)^{\varsigma}\left(\delta_{i}\right)^{\varsigma \tau} \mathrm{A}^{(\varsigma-1)(\tau+1)}
$$

It is then possible, for a fixed $\mu_{\mathrm{o}}$, to rewrite $c_{t}^{i}=\left(\lambda_{i}\right)^{\varsigma}\left(\delta_{i}\right)^{\varsigma t} \mathrm{~A}^{\varsigma(t+1)}\left(\mu_{\mathrm{o}}\right), i \in\{1,2\}$, as

$$
c_{t}^{i}=\frac{\left(\lambda_{i}\right)^{\varsigma}\left(\delta_{i}\right)^{\varsigma t} \mathrm{~A}^{\varsigma(t+1)} \mathrm{K}_{\mathrm{o}}^{-\varsigma}}{\sum_{\tau=0}^{+\infty} \sum_{j=1}^{2}\left(\lambda_{j}\right)^{\varsigma}\left(\delta_{j}\right)^{\varsigma \tau} \mathrm{A}^{(\varsigma-1)(\tau+1)}}, i \in\{1,2\} .
$$

In other words, $c_{t}^{i}$ grows at a rate of $\left(\delta_{i} \mathrm{~A}\right)^{\varsigma}$, so that the consumption growth are different for $\delta_{1} \neq \delta_{2}$.

Q.E.D.

\section{VI.5 Proof of Proposition III.3}

Proof: (i) Consider the problem

$$
\max \sum_{t=0}^{+\infty} \sum_{i=1}^{2} \lambda_{i}\left(\delta_{i}\right)^{t} \ln \left(c_{t}^{i}\right) \text { s.t. } \sum_{i=1}^{2} c_{t}^{i}+\mathrm{K}_{t+1}=\mathrm{AK}_{t}, \mathrm{~K}_{\mathrm{o}} \text { given. }
$$

The dynamic Lagrangean is

$$
\mathrm{L}_{t}=\sum_{i=1}^{2} \lambda_{i}\left(\delta_{i}\right)^{t} \ln \left(c_{t}^{i}\right)+\mu_{t+1}\left(\mathrm{AK}_{t}-\sum_{i=1}^{2} c_{t}^{i}\right)-\mu_{t} \mathrm{~K}_{t} .
$$

The necessary and sufficient conditions for an optimal trajectory are:

$$
\frac{\lambda_{i}\left(\delta_{i}\right)^{t}}{c_{t}^{i}}=\mu_{t+1}, i \in\{1,2\},
$$

(A.8c)

$$
\mu_{t}=A \mu_{t+1}
$$

$$
\lim _{t \rightarrow+\infty} \mu_{t} \mathrm{~K}_{t}=0
$$

Using the resource constraint together with equation (A.8a), we have:

(A.9) $\mathrm{K}_{t+1}=\mathrm{AK}_{t}-\sum_{i=1}^{2} \frac{\lambda_{i}\left(\delta_{i}\right)^{t}}{\mu_{t+1}}$

From (A.8b), $\mu_{t}=\mu_{\mathrm{o}} / \mathrm{A}^{t}$. Letting $k_{t}=\mathrm{K}_{t} / \mathrm{A}^{t}$, equations (A.8c) and (A.9) can be rewritten as:

$$
k_{t+1}=k_{t}-\frac{\sum_{i=1}^{2} \lambda_{i}\left(\delta_{i}\right)^{t}}{\mu_{0}}
$$




$$
\lim _{t \rightarrow+\infty} k_{t} \mu_{\mathrm{o}}=0 .
$$

We have:

$$
\begin{aligned}
k_{t} & =k_{t-1}-\frac{\sum_{i=1}^{2} \lambda_{i}\left(\delta_{i}\right)^{t-1}}{\mu_{\mathrm{o}}} \\
& =k_{\mathrm{O}}-\frac{1}{\mu_{\mathrm{o}}} \sum_{\tau=0}^{t-1} \sum_{i=1}^{2} \lambda_{i}\left(\delta_{i}\right)^{\tau} .
\end{aligned}
$$

Recalling that $\lim _{t \rightarrow+\infty} \mu_{\mathrm{o}} k_{t}=\mathrm{o}$, we obtain:

$$
\mu_{\mathrm{o}} k_{\mathrm{o}}=\sum_{\tau=0}^{+\infty} \sum_{i=1}^{2} \lambda_{i}\left(\delta_{i}\right)^{\tau}
$$

from which

$$
\begin{aligned}
\mu_{\mathrm{o}} & =\frac{\sum_{\tau=0}^{+\infty} \sum_{i=1}^{2} \lambda_{i}\left(\delta_{i}\right)^{\tau}}{k_{\mathrm{o}}} \\
& =\frac{1}{k_{\mathrm{o}}} \sum_{i=1}^{2} \frac{\lambda_{i}}{1-\delta_{i}} .
\end{aligned}
$$

Maximum utility is given by:

$$
\begin{aligned}
\sum_{t=0}^{+\infty} \sum_{i=1}^{2} \lambda_{i}\left(\delta_{i}\right)^{t} \ln \left[\frac{\lambda_{i}\left(\delta_{i}\right)^{t}}{\mu_{t+1}}\right]= & \sum_{t=0}^{+\infty} \sum_{i=1}^{2} \lambda_{i}\left(\delta_{i}\right)^{t} \ln \left(\lambda_{i}\right)+\sum_{t=0}^{+\infty} \sum_{i=1}^{2} \lambda_{i}\left(\delta_{i}\right)^{t} t \ln \left(\delta_{i}\right) \\
& +\sum_{t=0}^{+\infty} \sum_{i=1}^{2} \lambda_{i}\left(\delta_{i}\right)^{t}(t+1) \ln (\mathrm{A})-\sum_{t=0}^{+\infty} \sum_{i=1}^{2} \lambda_{i}\left(\delta_{i}\right)^{t} \ln \left(\mu_{\mathrm{o}}\right) \\
= & \sum_{i}^{2} \Delta_{i}+\sum_{i=1}^{2} \mathrm{M}_{i}+\sum_{i}^{2} \Gamma_{i}-\sum_{i}^{2} \Gamma_{i}^{\prime}
\end{aligned}
$$

After some simplifications:

$$
\begin{aligned}
\Delta_{i} & =\sum_{t=0}^{+\infty} \lambda_{i}\left(\delta_{i}\right)^{t} \ln \left(\lambda_{i}\right) \\
& =\frac{\lambda_{i} \ln \left(\lambda_{i}\right)}{1-\delta_{i}} ; \\
\mathrm{M}_{i} & =\sum_{t=0}^{+\infty} \lambda_{i}\left(\delta_{i}\right)^{t} t \ln \left(\delta_{i}\right) \\
& =\lambda_{i} \ln \left(\delta_{i}\right) \sum_{t=0}^{+\infty}\left(\delta_{i}\right)^{t} t \\
& =\lambda_{i} \ln \left(\delta_{i}\right) \frac{\delta_{i}}{\left(1-\delta_{i}\right)^{2}} ; \\
\Gamma_{i} & =\sum_{t=0}^{+\infty} \lambda_{i}\left(\delta_{i}\right)^{t}(t+1) \ln (\mathrm{A}) \\
& =\frac{\lambda_{i} \ln (\mathrm{A})}{1-\delta_{i}}+\lambda_{i} \ln (\mathrm{A}) \frac{\delta_{i}}{\left(1-\delta_{i}\right)^{2}} \\
& =\frac{\lambda_{i} \ln (\mathrm{A})}{\left(1-\delta_{i}\right)^{2}} ; \\
\Gamma_{i}^{\prime} & =-\sum_{t=0}^{+\infty} \lambda_{i}\left(\delta_{i}\right)^{t} \ln \left(\mu_{\mathrm{o}}\right)
\end{aligned}
$$




$$
\begin{aligned}
& =-\frac{\lambda_{i} \ln \left(\mu_{\mathrm{o}}\right)}{1-\delta_{i}} \\
& =\frac{\lambda_{i} \ln \left(k_{\mathrm{o}}\right)}{1-\delta_{i}}-\frac{\lambda_{i}}{1-\delta_{i}} \ln \left(\sum_{j=1}^{2} \frac{\lambda_{j}}{1-\delta_{j}}\right) .
\end{aligned}
$$

So that inter-temporal welfare is:

$$
\begin{aligned}
& \mathrm{U}=\sum_{i=1}^{2} \lambda_{i} \mathrm{U}_{i}, \\
& \mathrm{U}_{i}=\frac{\ln \left(\lambda_{i}\right)}{1-\delta_{i}}+\ln \left(\delta_{i}\right) \frac{\delta_{i}}{\left(1-\delta_{i}\right)^{2}}+\frac{\ln (\mathrm{A})}{\left(1-\delta_{i}\right)^{2}}+\frac{\ln \left(k_{\mathrm{o}}\right)}{1-\delta_{i}}-\frac{\ln \left[\sum_{j=1}^{2}\left[\lambda_{j} /\left(1-\delta_{j}\right)\right]\right]}{1-\delta_{i}} .
\end{aligned}
$$

On the contrary, the payoffs from the temporally-consistent solution come from the following reworked system of first-order conditions:

$$
\begin{aligned}
c_{t+\tau}^{i} & =\frac{\left(\lambda_{i} / \mu\right) \mathrm{AK}_{t+\tau}}{1+1 / \mu} \\
& =\frac{\lambda_{i} \mathrm{AK}_{t+\tau}}{1+\mu} \\
& =\frac{\lambda_{i} \mathrm{~A}}{1+\mu}\left(\frac{\mathrm{A}}{\mathrm{B}(\mu)}\right)^{\tau}, \mathrm{K}_{t} \\
\mathrm{~K}_{t+\tau} & =\left(\frac{\mathrm{A}}{\mathrm{B}(\mu)}\right)^{\tau} \mathrm{K}_{t},
\end{aligned}
$$

for $\mathrm{B}(\mu)=(\mu+1) / \mu$ and $\mu=\sum_{i=1}^{2} \lambda_{i} a_{i} \delta_{i}$. Taking the approach of Example 1 and Proposition III.1, the inter-temporal payoff functions are log and can be calculated as:

$$
\begin{aligned}
J^{i}\left(\mathrm{~K}_{\mathrm{o}}\right) & =\sum_{\tau=0}^{+\infty}\left(\delta_{i}\right)^{\tau} \ln \left[\frac{\lambda_{i} \mathrm{~A}}{1+\mu}\left(\frac{\mathrm{A}}{\mathrm{B}(\mu)}\right)^{\tau} \mathrm{K}_{\mathrm{o}}\right] ; \\
& =\frac{\ln \left[\lambda_{i} \mathrm{AK} \mathrm{K}_{\mathrm{o}} /(1+\mu)\right]}{1-\delta_{i}}+\sum_{\tau=0}^{+\infty}\left(\delta_{i}\right)^{\tau} \tau \ln \left(\frac{\mathrm{A}}{\mathrm{B}(\mu)}\right) \\
& =\frac{\ln \left[\lambda_{i} \mathrm{AK} \mathrm{K}_{\mathrm{o}} /(1+\mu)\right]}{1-\delta_{i}}+\frac{\delta_{i}}{1-\delta_{i}},
\end{aligned}
$$

from which, comparing to the conjectured $\mathrm{J}^{i}(\mathrm{~K})=a_{i} \ln (\mathrm{K})+b_{i}$, we have $a_{i}=1 /\left(1-\delta_{i}\right)$, $\mu=\sum_{i=1}^{2} \lambda_{i} \delta_{i} /\left(1-\delta_{i}\right)$ and $\mathrm{B}(\mu)=\sum_{i=1}^{2}\left[\lambda_{i} /\left(1-\delta_{i}\right)\right] / \sum_{i=1}^{2}\left[\lambda_{i} \delta_{i} /\left(1-\delta_{i}\right)\right]$.

After further calculation, the temporally-consistent payoff functions can hence be derived as:

$$
\mathrm{J}^{i}\left(\mathrm{~K}_{\mathrm{o}}\right)=\frac{\ln \left(\mathrm{K}_{\mathrm{o}}\right)}{1-\delta_{i}}+\frac{\ln \left(\lambda_{i}\right)}{1-\delta_{i}}+\frac{\ln (\mathrm{A})}{\left(1-\delta_{i}\right)^{2}}-\frac{\ln (1+\mu)}{\left(1-\delta_{i}\right)^{2}}+\frac{\delta_{i} \ln (\mu)}{\left(1-\delta_{i}\right)^{2}}, \quad i \in\{1,2\} .
$$

Comparing the payoffs of the temporally-consistent and -inconsistent solutions, and first considering the relatively patient agent, $i=1$, we have:

$$
\begin{aligned}
\mathrm{J}^{1}\left(\mathrm{~K}_{\mathrm{o}}\right)-\mathrm{U}_{1} & =\frac{\delta_{1}}{\left(1-\delta_{1}\right)^{2}}\left\{\ln \left[\frac{\sum_{j=1}^{2}\left[\lambda_{j} \delta_{j} /\left(1-\delta_{j}\right)\right]}{\sum_{j=1}^{2}\left[\lambda_{j} /\left(1-\delta_{j}\right)\right]}\right]-\ln \left(\delta_{1}\right)\right\} \\
& <\mathrm{o},
\end{aligned}
$$

where the last inequality results from $\delta_{2}<\delta_{1}$ as the expression between curly brackets can be rewritten as $\lambda_{2} \delta_{2} /\left(1-\delta_{2}\right)<\lambda_{2} \delta_{1} /\left(1-\delta_{2}\right)$ being negative. 
Considering then the relatively patient agent $i=2$, it can be shown that:

$$
\begin{aligned}
\mathrm{J}^{2}\left(\mathrm{~K}_{\mathrm{o}}\right)-\mathrm{U}_{2} & =\frac{\delta_{2}}{\left(1-\delta_{2}\right)^{2}}\left\{\ln \left[\frac{\sum_{j=1}^{2}\left[\lambda_{j} \delta_{j} /\left(1-\delta_{j}\right)\right]}{\sum_{j=1}^{2}\left[\lambda_{j} /\left(1-\delta_{j}\right)\right]}\right]-\ln \left(\delta_{2}\right)\right\} \\
& >0
\end{aligned}
$$

where the last inequality results from $\delta_{2}<\delta_{1}$ as the expression between curly brackets can be rewritten as $\lambda_{1} \delta_{1} /\left(1-\delta_{1}\right)>\lambda_{1} \delta_{2} /\left(1-\delta_{1}\right)$ being positive.

Finally, considering total welfare in the economy, and letting $\lambda_{1}=\lambda$ and $\lambda_{2}=1-\lambda$, we have:

$$
\begin{aligned}
\sum_{i=1}^{2} \lambda_{i}\left[J^{i}\left(K_{0}\right)-U_{i}\right] & =\lambda\left[J^{1}\left(K_{0}\right)-U_{1}\right]+(1-\lambda)\left[J^{2}\left(K_{0}\right)-U_{2}\right] \\
& :=\varphi(\lambda),
\end{aligned}
$$

where it can be noted that $\varphi(0)=\varphi(1)=0$. Further calculations allow us to establish that

$$
\begin{aligned}
D^{2} \varphi(\lambda) & =\frac{2\left(\delta_{1}-\delta_{2}\right)}{\left(1-\delta_{1}\right)\left(1-\delta_{2}\right)\left[\lambda /\left(1-\delta_{1}\right)+(1-\lambda) /\left(1-\delta_{2}\right)\right]^{3}} \\
& \quad \times\left\{\frac{1}{\left(1-\delta_{1}\right)\left(1-\delta_{2}\right)}\left[\frac{\delta_{1}}{1-\delta_{1}}-\frac{\delta_{2}}{1-\delta_{2}}\right]\right\} \\
& >0
\end{aligned}
$$

and that $\varphi(\cdot)$ is a convex function for any $\lambda \in] 0,1[$. As such, and for any $\lambda \in] 0,1[, \varphi(\lambda)<0$. The consideration of temporally-consistent decision rules for the welfare of the agents leads to an overall loss of welfare.

Q.E.D.

\section{VI.6 Proof of Lemma IV.1}

Proof: Consider the following generalized Lagrangian:

$$
\mathscr{L}_{t}=\Delta_{t} \sum_{i=1}^{n} \lambda_{i} u^{i}\left(c_{t}^{i}\right)+\mu_{t+1}\left[\mathrm{~F}\left(\mathrm{~K}_{t}, 1\right)+(1-\eta) \mathrm{K}_{t}-\sum_{i=1}^{n} c_{t}^{i}\right]-\mu_{t} \mathrm{~K}_{t}
$$

The optimality conditions derive as:

$$
\begin{aligned}
& \Delta_{t} \lambda_{i} \mathrm{D} u^{i}\left(c_{t}^{i}\right)=\mu_{t+1}, \\
& \mu_{t}=\mu_{t+1}\left[\mathrm{D}_{\mathrm{K}} \mathrm{F}\left(\mathrm{K}_{t}, 1\right)+1-\eta\right], \\
& \lim _{t \rightarrow+\infty} \mu_{t} \mathrm{~K}_{t}=0 .
\end{aligned}
$$

Rearranging and eliminating the multiplier $\mu_{t}$ between these equations, it is obtained that:

$$
\begin{aligned}
& \lambda_{i} \mathrm{D} u^{i}\left(c_{t}^{i}\right)=\lambda_{j} \mathrm{D} u^{j}\left(c_{t}^{j}\right), \\
& \mathrm{D} u^{i}\left(c_{t-1}^{i}\right)=\delta_{t-1}\left[\mathrm{D}_{\mathrm{K}} \mathrm{F}\left(\mathrm{K}_{t}, 1\right)+1-\eta\right] \mathrm{D} u^{i}\left(c_{t}^{i}\right), \\
& \lim _{t \rightarrow+\infty} \Delta_{t} \mathrm{D} u^{i}\left(c_{t}^{i}\right)\left[\mathrm{D}_{\mathrm{K}} \mathrm{F}\left(\mathrm{K}_{t}, 1\right)+1-\eta\right]=0, \\
& \mathrm{~K}_{t+1}=\mathrm{F}\left(\mathrm{K}_{t}, 1\right)+(1-\eta) \mathrm{K}_{t}-\sum_{i=1}^{n} c_{t}^{i} .
\end{aligned}
$$

The statement follows. 


\section{VI.7 Proof of Proposition IV.1}

Proof: The argument of the proof proceeds by establishing that $\left(\mathrm{K}_{t}^{*}, c_{t}^{i *}\right)_{t \in \mathbb{N}, i \in\{1,2, \ldots, n\}}$ corresponds to a solution to the system defined by equations $(14 \mathrm{a}),(14 \mathrm{~b}),(14 \mathrm{c}),(14 \mathrm{~d})$ and (15)

Equation (14a) holds because

$$
\lambda_{i} \mathrm{D} u^{i}\left(c_{t}^{i *}\right)=\lambda_{j} \mathrm{D} u^{j}\left(c_{t}^{j *}\right)
$$

as a result of $(9)$.

Equation $(14 \mathrm{~b})$ is satisfied because the consideration of $(8)$ at dates $t$ and $t-1$ delivers:

$$
\begin{aligned}
& \mathrm{D} u^{i}\left(c_{t}^{i *}\right)=\mathrm{DW}^{\Delta}\left(\mathrm{K}_{t+1}^{*}\right), \\
& \mathrm{D} u^{i}\left(c_{t-1}^{i *}\right)=\mathrm{DW}^{\Delta}\left(\mathrm{K}_{t}^{*}\right),
\end{aligned}
$$

whence:

$$
\frac{\mathrm{D} u^{i}\left(c_{t-1}^{i *}\right)}{\mathrm{D} u^{i}\left(c_{t}^{i *}\right)}=\frac{\mathrm{DW}^{\Delta}\left(\mathrm{K}_{t}^{*}\right)}{\mathrm{DW}^{\Delta}\left(\mathrm{K}_{t+1}^{*}\right)} .
$$

Making then use of (11):

$$
\frac{\mathrm{D} u^{i}\left(c_{t-1}^{i *}\right)}{\mathrm{D} u^{i}\left(c_{t}^{i *}\right)}=\frac{\mathrm{DW}^{\Delta}\left(\mathrm{K}_{t}^{*}\right)}{\mathrm{DW}\left(\mathrm{K}_{t}^{*}\right)}\left[\mathrm{D}_{\mathrm{K}} \mathrm{F}\left(\mathrm{K}_{t}^{*}, 1\right)+1-\eta\right] .
$$

As $\lim _{t \rightarrow+\infty} \Delta_{t}=0$, Equation (14c) is satisfied as soon as $c_{t}^{i *}, i \in\{1,2, \ldots, n\}$ and $\mathrm{K}_{t}^{*}$ converge toward non-zero stationary values. Finally, Equation (14d) is satisfied by construction. The statement follows.

Q.E.D.

\section{VI.8 Proof of Corollary IV.1}

Proof: From Proposition II.1, it is first obtained that:

$$
\begin{aligned}
\delta & =\frac{\mathrm{DW}^{\Delta}(\mathrm{K})}{\mathrm{DW}(\mathrm{K})} \\
& =\frac{\sum_{i=1}^{2} \alpha \delta_{i} \lambda_{i} /\left(1-\alpha \delta_{i}\right)}{\sum_{i=1}^{2} \alpha \lambda_{i} /\left(1-\alpha \delta_{i}\right)} \\
& =\frac{\sum_{i=1}^{2} \delta_{i} \lambda_{i} /\left(1-\alpha \delta_{i}\right)}{\sum_{i=1}^{2} \lambda_{i} /\left(1-\alpha \delta_{i}\right)} .
\end{aligned}
$$

It is further clear that the value function of the planner's program $(\mathscr{P})$, denoted as $\mathrm{W}^{p}\left(\mathrm{~K}_{\mathrm{o}}\right)$, assumes the following form:

$$
\mathrm{W}^{p}\left(\mathrm{~K}_{\mathrm{o}}\right)=\nu \ln \left(\mathrm{K}_{\mathrm{o}}\right)+b .
$$

It satisfies the Bellman equation:

$$
\begin{array}{r}
\mathrm{W}^{p}\left(\mathrm{~K}_{t}\right)=\max _{\left\{c_{t}^{i}, \mathrm{~K}_{t}\right\}} \sum_{i=1}^{2} \ln \left(c_{t}^{i}\right)+\delta \mathrm{W}^{p}\left(\mathrm{~K}_{t+1}\right) \\
\text { s.t. } \quad \mathrm{K}_{t+1}=\mathrm{A}\left(\mathrm{K}_{t}\right)^{\alpha}-\sum_{i=1}^{2} c_{t}^{i} .
\end{array}
$$


The first order conditions of this program restate as:

$$
c_{t}^{i}=\frac{\lambda_{i} K_{t+1}}{\delta \nu} .
$$

Replacing into the resource constraint, it is obtained that:

$$
\begin{aligned}
& \mathrm{K}_{t+1}=\frac{\delta \nu}{1+\delta \nu} \mathrm{A}\left(\mathrm{K}_{t}\right)^{\alpha}, \\
& c_{t}^{i}=\frac{\lambda_{i}}{1+\delta \nu} \mathrm{A}\left(\mathrm{K}_{t}\right)^{\alpha} .
\end{aligned}
$$

The analytical formulation of the value function of the planner's program can then be computed to:

$$
W^{p}\left(K_{t}\right)=\sum_{\tau=0}^{+\infty} \delta^{\tau}\left[\alpha \ln \left(K_{t+\tau}\right)+\sum_{i=1}^{2} \lambda_{i} \ln \left(\frac{\lambda_{i}}{1+\delta \nu}\right)\right] .
$$

It is finally obtained that:

$$
\mathrm{W}^{p}\left(\mathrm{~K}_{t}\right)=\frac{\alpha}{1-\alpha \delta} \ln \left(\mathrm{K}_{t}\right)+b,
$$

where $b$ is a constant term. In order to check that $W^{p}\left(K_{t}\right)=W\left(K_{t}\right)$, it then suffices to check that:

$$
\frac{\alpha}{1-\alpha \delta}=\sum_{i=1}^{2} \frac{\alpha \lambda_{i}}{1-\alpha \delta_{i}}
$$

It is first noticed that this equation equivalently reformulates to:

$$
\frac{1}{1-\alpha \delta}=\sum_{i=1}^{2} \frac{\lambda_{i}}{1-\alpha \delta_{i}}
$$

or

$$
\frac{1}{1-\alpha \sum_{i=1}^{2}\left[\lambda_{i} \delta_{i} /\left(1-\alpha \delta_{i}\right)\right] / \sum_{i=1}^{2}\left[\lambda_{i} /\left(1-\alpha \delta_{i}\right)\right]}=\sum_{i=1}^{2} \frac{\lambda_{i}}{1-\alpha \delta_{i}},
$$

whence

$$
\frac{1}{\sum_{i=1}^{2}\left[\lambda_{i} /\left(1-\alpha \delta_{i}\right)\right]-\alpha \sum_{i=1}^{2}\left[\lambda_{i} \delta_{i} /\left(1-\alpha \delta_{i}\right)\right]}=1,
$$

or

$$
\sum_{i=1}^{2} \frac{\lambda_{i}\left(1-\alpha \delta_{i}\right)}{1-\alpha \delta_{i}}=1
$$

Finally, $\sum_{i=1}^{2} \lambda_{i}=1$, that holds under the assumptions of the model.

\section{VI.9 Proof of Proposition V.1}

Proof: (i) The argument of the proof is developed by establishing that any of the conditions (16a) $-(16 \mathrm{k})$ are satisfied when $\mathrm{K}_{t}=\mathrm{K}_{t}^{*}, c_{t}^{i}=c_{t}^{i *}$ for any $i \in\{1,2, \ldots, n\}, t \in \mathbb{N}$ and with the policy instruments defined by equations $(17 \mathrm{a})-(17 \mathrm{~b}),(17 \mathrm{c})-(17 \mathrm{~d}),(18)$, and $(19 \mathrm{a})-(19 \mathrm{~b})$ Equation $(16 \mathrm{a})$ can be shown to be satisfied from the definition of $X_{t}^{i}$ : making use of $(8)$ considered at date $t-1$, it is readily seen that

$$
\frac{\mathrm{D} u^{i}\left(c_{t}^{i *}\right)}{\mathrm{D} u^{i}\left(c_{t-1}^{i *}\right)}=\frac{\mathrm{DW}^{\Delta}\left(\mathrm{K}_{t+1}^{*}\right)}{\mathrm{DW}^{\Delta}\left(\mathrm{K}_{t}^{*}\right)} \text {. }
$$


Appealing to the envelope condition (11), the R.H.S. of the above equation can be rewritten as:

$$
\frac{\mathrm{DW}^{\Delta}\left(\mathrm{K}_{t+1}^{*}\right)}{\mathrm{DW}^{\Delta}\left(\mathrm{K}_{t}^{*}\right)}=\frac{\mathrm{DW}\left(\mathrm{K}_{t}^{*}\right)}{\mathrm{DW}^{\Delta}\left(\mathrm{K}_{t}^{*}\right)} \frac{1}{\mathrm{R}\left(\mathrm{K}_{t}^{*}\right)},
$$

hence, finally:

$$
\frac{\mathrm{D} u^{i}\left(c_{t}^{i *}\right)}{\mathrm{D} u^{i}\left(c_{t-1}^{i *}\right)}=\frac{1}{\mathrm{X}_{t}^{i} \delta_{i}} \frac{1}{\mathrm{R}\left(\mathrm{K}_{t}^{*}\right)}
$$

which results in $(16 \mathrm{a})$.

Equations (16b) and (16c) hold from the construction of the argument, the coefficient $\mathrm{T}_{\mathrm{o}}^{i}$ being defined in order for $(16 \mathrm{~d})$ to hold. Equations (16e), (16g) and (16h) are similarly satisfied from the structure of the argument, while (16h) corresponds to the resource constraint of the economy. While equation ( $16 \mathrm{j})$ is satisfied from the structure of the argument, equation (16i) can be established through a recursive argument. By date $t=1$, making use of equation $(16 \mathrm{c})$, can be shown that:

$$
\sum_{i=1}^{n} a_{1}^{i}=\mathrm{R}\left(\mathrm{K}_{\mathrm{o}}^{*}\right) \sum_{i=1}^{n} \mathrm{X}_{\mathrm{o}}^{i}\left(a_{\mathrm{o}}^{i}+\mathrm{T}_{\mathrm{o}}^{i}\right)+\mathrm{D}_{\mathrm{L}} \mathrm{F}\left(\mathrm{K}_{\mathrm{o}}^{*}, 1\right)-\sum_{i=1}^{n} c_{\mathrm{o}}^{i}
$$

Subtracting $(16 \mathrm{~g})$ from the above equation yields:

$$
\sum_{i=1}^{n} a_{1}^{i}-b_{1}=\mathrm{R}\left(\mathrm{K}_{\mathrm{o}}^{*}\right) \sum_{i=1}^{n}\left(a_{\mathrm{o}}^{i}+\mathrm{T}_{\mathrm{o}}^{i}\right)-\mathrm{R}\left(\mathrm{K}_{\mathrm{o}}^{*}\right) b_{\mathrm{o}}+\mathrm{D}_{\mathrm{L}} \mathrm{F}\left(\mathrm{K}_{\mathrm{o}}^{*}, 1\right)-\sum_{i=1}^{n} c_{\mathrm{o}}^{i *}
$$

which in turn can be rewritten, making use of $\sum_{i=1}^{n}\left(a_{\mathrm{o}}^{i}+\mathrm{T}_{\mathrm{o}}^{i}\right)=\mathrm{K}_{\mathrm{o}}^{*}+b_{\mathrm{o}} \operatorname{derived}$ from $(16 \mathrm{j})$, as:

$$
\sum_{i=1}^{n} a_{1}^{i}-b_{1}=\mathrm{R}\left(\mathrm{K}_{\mathrm{o}}^{*}\right)\left(\mathrm{K}_{\mathrm{o}}^{*}+b_{\mathrm{o}}\right)-\mathrm{R}\left(\mathrm{K}_{\mathrm{o}}^{*}\right) b_{\mathrm{o}}+\mathrm{D}_{\mathrm{L}} \mathrm{F}\left(\mathrm{K}_{\mathrm{o}}^{*}, 1\right)-\sum_{i=1}^{n} c_{\mathrm{o}}^{i *} .
$$

Finally:

$$
\begin{aligned}
\sum_{i=1}^{n} a_{1}^{i}-b_{1} & =\mathrm{F}\left(\mathrm{K}_{\mathrm{o}}^{*}, 1\right)+(1-\eta) \mathrm{K}_{\mathrm{o}}^{*}-\sum_{i=1}^{n} c_{\mathrm{o}}^{i *} \\
& =\mathrm{K}_{1}^{*} .
\end{aligned}
$$

Such a line of argumentation can then be extended between period $t$ and period $t+1$. Equation (16k) finally prevails from the building of the argument.

(ii) Consider the stationary state $\left(\mathrm{K}^{*}, c^{i *}\right)$ that is associated with capital taxation instruments $X^{i}, i \in\{1,2, \ldots, n\}$. Equation $(16 a)$ then reformulates to:

$$
\mathrm{X}^{i} \delta_{i}=\frac{1}{\mathrm{R}\left(\mathrm{K}^{*}\right)}
$$

From Proposition II.1, it is derived that:

$$
\begin{aligned}
\delta_{n} & <\frac{1}{\mathrm{R}\left(\mathrm{K}^{*}\right)} \\
& <\delta_{1},
\end{aligned}
$$

whence the asserted holding of $X^{1}<1$ and $X^{n}>1$. 